\title{
1 ATUAÇÃO DE BANCOS ESTRANGEIROS NO BRASIL: MERCADOS DE CRÉDITO E DERIVATIVOS DE 2005 A $201 I$
}

\section{RAQUEL DE FREITAS OLIVEIRA}

Doutora em Administração pela Faculdade de Economia, Administração e Contabilidade da Universidade de São Paulo (FEA-USP).

Professora do Departamento de Administração da Fundação Escola de Comércio Álvares Penteado (Fecap). Avenida da Liberdade, 532, Liberdade - SP - Brasil - CEP 01503-000

E-mail: raquel.oliveira@bcb.gov.br

\section{RAFAEL FELIPE SCHIOZER}

Doutor em Finanças pela Escola de Administração de Empresas de São Paulo da Fundação Getulio Vargas (Eaesp-FGV).

Professor do Departamento de Contabilidade, Finanças e Controle da Fundação Getulio Vargas.

Avenida Nove de Julho, 2.029, Bela Vista, São Paulo - SP - Brasil - CEP 01313-902

E-mail: rafael.schiozer@fgv.br

\section{SÉRGIO LEÃO}

Doutor em Economia pelo Departamento de Economia da Pontifícia Universidade Católica do Rio de Janeiro (PUC-Rio).

Analista do Departamento de Monitoramento do Sistema Financeiro do Banco Central do Brasil. Avenida Presidente Vargas, 730, $19^{\circ}$ andar, torre 2, Centro, Rio de Janeiro - RJ - Brasil - CEP 20071-900

E-mail: sergio.leao@bcb.gov.br 


\section{RESUMO}

Este estudo insere-se no debate a respeito das consequências da presença de bancos estrangeiros em países em desenvolvimento. Especificamente, é investigada a atuação do conjunto de bancos de controle estrangeiro no Brasil de 2005 a 20II, com foco em sua participação nos mercados de crédito e de derivativos cambiais. Verificaram-se ainda os impactos da crise financeira internacional de 2008/2009 sobre o comportamento desses bancos. A motivação para essa análise está nos papéis que o crédito e a gestão de riscos financeiros desempenham no desenvolvimento econômico. O crédito é um canal fundamental de atuação pelo qual os bancos estrangeiros podem afetar o crescimento da economia doméstica. Os derivativos cambiais fazem parte de importante conjunto de tecnologias para gestão de risco das empresas e investidores que são mais comumente oferecidos pelos bancos estrangeiros e ajudam a explicar os efeitos benéficos da presença desses tipos de banco em economias emergentes. No período amostral, os bancos estrangeiros respondem por pouco mais de um quarto das concessões de crédito livre. Embora os testes realizados não permitam concluir relações de causa e efeito entre variáveis, observa-se que a crise financeira afetou negativamente os bancos estrangeiros, de forma mais intensa e longa do que os bancos privados nacionais. Essa observação pode ser indicativa de uma transmissão do choque de liquidez ocorrido nos mercados desenvolvidos para a economia brasileira. Entretanto, no período pós-crise, a partir do terceiro trimestre de 20 Io até o final de 20II, a taxa de crescimento das concessões dos estrangeiros foi superior às dos demais. No mercado de derivativos cambiais, os bancos estrangeiros, inclusive os de menor porte, têm papel importante no fornecimento desses instrumentos, especialmente para o setor não financeiro. Os resultados mostram que, durante a crise, e, especialmente, no período pós-crise, os bancos privados nacionais diminuíram sua atuação nesses mercados. Adicionalmente, mostra-se que esse mercado é menos concentrado que o de crédito, o que evidencia a importância da existência de instituições financeiras de menor porte. 


\section{PALAVRAS-CHAVE}

Bancos estrangeiros. Crédito. Derivativos cambiais. Transmissão de crise. Economia brasileira.

\section{INTRODUÇÃO}

Há um intenso debate a respeito das consequências da presença de bancos estrangeiros em países em desenvolvimento ${ }^{\mathrm{I}}$. Parte da literatura argumenta que a presença de bancos estrangeiros em países emergentes aumenta seu desenvolvimento financeiro, relacionando-se, portanto, à taxa futura de crescimento econômico (Levine, I996; Mishkin, 2006; Goldberg, 2009). Contrariamente, outra parte da literatura destaca que a presença de bancos estrangeiros pode prejudicar o crescimento macroeconômico ao desestabilizar o sistema financeiro (Stiglitz, 2005; Rodrik \& Subramanian, 2009).

Essa discussão torna-se ainda mais importante a partir da crise de 2008 , pois evidências empíricas apontam que os bancos estrangeiros podem transferir os choques e ciclos econômicos de seus países de origem para os países emergentes em que operam (Popov \& Udell, 20Iо; Cetorelli \& Goldberg, 20II; Allen, Hryckiewicz, Kowalewski, \& Tumer-Alkan, 20ı2; Montoro \& Rojas-Suarez, 20I2).

Este artigo descreve a atuação dos bancos sob controle estrangeiro que atuam no Brasil e investiga os impactos da crise financeira internacional de 2008/2009 sobre o comportamento desses bancos. O foco do estudo está em dois tipos de serviços financeiros: a concessão de empréstimos e a oferta de instrumentos financeiros derivativos cambiais. A motivação para esse tipo de análise está no papel que o crédito e a gestão de riscos financeiros desempenham no desenvolvimento econômico. O crédito é um canal fundamental de atuação pelo qual os bancos estrangeiros podem afetar o crescimento da economia doméstica. Os derivativos cambiais fazem parte de importante conjunto de tecnologias para gestão de risco das empresas e investidores que são mais comumente oferecidos pelos bancos estrangeiros e ajudam a explicar os efeitos benéficos da presença desses tipos de banco em economias emergentes.

O período amostral vai de 2005 a $201 \mathrm{I}$, o que permite observar possíveis alterações de comportamento resultantes da crise de 2008/2009. Como uma

Claessens e Van Horen (20I2) e Cull e Martinez Peria (20I0) apresentam levantamentos recentes sobre o assunto. 
exploração inicial das diferenças de comportamento entre bancos estrangeiros e domésticos, este estudo foca em testes de média e regressões por mínimos quadrados ordinários, deixando questões de endogeneidade e viés de variáveis omitidas para pesquisas futuras.

Analisam-se os volumes e as taxas de juros das concessões de crédito livres ${ }^{2}$, que são as operações sobre as quais os bancos têm maior autonomia de decisão, com o objetivo de investigar como o choque de liquidez internacional durante a crise de 2008/2009 afetou o sistema bancário brasileiro. Especificamente, verifica-se que bancos estrangeiros e nacionais reagiram de forma diferente à crise: os bancos estrangeiros diminuíram sua participação no mercado de crédito durante a crise e, já no final do período pós-crise, recuperaram parte dessa participação. Essa análise está relacionada aos estudos que investigam a transmissão de choques e ciclos econômicos dos bancos controladores para suas subsidiárias estrangeiras, com consequências negativas na concessão de empréstimos (Chava \& Purnanandam, 20II; Montoro \& Rojas-Suarez, 20I2).

Adicionalmente, investiga-se a participação dos bancos estrangeiros no mercado de derivativos cambiais, análise que está relacionada aos estudos que teorizam sobre a sofisticação tecnológica e prestação de serviços de alta qualidade por bancos estrangeiros (Levine, I996; Claessens \& Van Horen, 20I2). Tanto quanto é de nosso conhecimento, este é o primeiro estudo a utilizar microdados de derivativos cambiais negociados nos mercados de bolsa e de balcão no Brasil, o que permite investigar a atuação de bancos nacionais e estrangeiros como contraparte nesses mercados. Os resultados mostram que os bancos estrangeiros são os principais fornecedores desses instrumentos junto a contrapartes não financeiras e investidores institucionais e que, embora esse mercado tenha diminuído em tamanho logo após a extrema desvalorização do real ocorrida ao final de 2008, os bancos estrangeiros aumentaram sua participação nesse mercado. Além disso, a análise sobre concentração de mercado indica que o mercado de fornecimento de derivativos cambiais é menos concentrado que o mercado de crédito, sugerindo um papel importante para os bancos de menor porte.

A próxima seção apresenta uma visão geral da literatura. A seção 3 descreve os dados e delimita as amostras utilizadas no estudo. A seção 4 apresenta a metodologia adotada. A seção 5 analisa o mercado de créditos livres. Na seção 6, realiza-se análise descritiva semelhante para o mercado de derivativos cambiais. A seção 7 trata da concentração dos mercados de créditos livres e derivativos cambiais. A seção 8 apresenta as considerações finais.

Crédito com recursos livres são aqueles que não possuem destinação especificada em lei ou normativo, como é o caso dos direcionados. 


\section{EFEITOS DA PRESENÇA DE BANCOS ESTRANGEIROS}

Grande parte da literatura sobre os efeitos da presença de bancos estrangeiros analisa os mercados americanos e europeus, mas há também alguns estudos que analisam mercados em desenvolvimento, inclusive o brasileiro.

\subsection{EVIDÊNCIAS NO EXTERIOR}

De modo geral, a literatura considera que bancos estrangeiros beneficiam os países que os recebem, pois promovem o desenvolvimento financeiro ao oferecerem ao mercado doméstico, além de crédito, serviços financeiros sofisticados, como o acesso a mercados internacionais e a oferta de produtos de gestão de risco. Adicionalmente, o aumento da concorrência advindo da entrada de estrangeiros exerce pressão sobre os preços desses serviços e estimula os bancos domésticos a melhorar sua eficiência e produtividade (Levine, I996; Claessens, Demirgüç-Kunt, \& Huizinga, 20or; Clarke, Cull, Martinez Peria, \& Sanchez, 2003; Goldberg, 2009; Cull \& Martinez Peria, 2010).

Adicionalmente, alguns estudos também destacam que bancos estrangeiros podem contribuir para melhorar o processo de supervisão bancária e aumentar a solidez do sistema financeiro (Levine, I996; Crystal, Dages, \& Goldberg, 200I; Martinez Peria \& Mody, 2004). Nesse sentido, há evidências empíricas de que as operações de crédito de bancos estrangeiros podem ser um mecanismo estabilizador em resposta a choques locais, como observam Cetorelli e Goldberg (20I2), De Haas e Van Lelyveld (20I0), Martinez Peria, Powell e Vladkova Hollar (2002) e Schnabl (2012).

Entretanto, outros estudos apontam desvantagens da presença de bancos estrangeiros. Um dos motivos relaciona-se ao fato de que, em geral, os bancos estrangeiros concedem crédito prioritariamente a grandes empresas, provavelmente devido à menor assimetria informacional. Se, com a entrada dos estrangeiros, os bancos domésticos continuam a emprestar aos clientes menores (mais opacos), não haveria destruição de riqueza, e sim, apenas, uma segmentação do mercado. Contudo, se a entrada de bancos estrangeiros fizer com que os bancos domésticos diminuam a oferta de crédito - pois restaria a eles apenas os clientes menores e mais arriscados, - a continuidade dos bancos domésticos no mercado ficará prejudicada, assim como o crescimento econômico, devido à maior restrição de capital das empresas pequenas e médias (Beck \& Martinez Peria, 2007; Detragiache, Tressel, \& Gupta, 2008).

Outra razão pela qual a presença de estrangeiros pode ser prejudicial está relacionada à literatura de transmissão de choques e ciclos econômicos. Essa literatura 
aponta que choques nos países de origem dos bancos estrangeiros podem ser transmitidos às suas subsidiárias, reduzindo suas concessões de créditos. As evidências nesse sentido têm-se avolumado desde o início da crise financeira global, como se vê nos estudos de Popov e Udell (20I0), Cetorelli e Goldberg (20II), De Haas e Van Lelyveld (20II), Allen et al. (20I2) e Montoro e Rojas-Suarez (2OI2). Contudo, Claessens e Van Horen (20I2) notam que essa maior redução do crédito dos bancos estrangeiros durante a crise não foi observada nos países em que esse tipo de banco dominava o sistema bancário. Além disso, a questão dos efeitos de um choque externo sobre o crédito doméstico parece mais complexa do que a origem do capital controlador. Por exemplo, Schnabl (20I2) identifica que os efeitos negativos da crise russa sobre o crédito no Peru foram menores para os bancos estrangeiros do que para os bancos domésticos que se financiavam internacionalmente.

\subsection{EVIDÊNCIAS NO BRASIL}

Os estudos acerca da presença do capital estrangeiro no mercado bancário brasileiro pós-Plano Real focam as questões da rentabilidade e da eficiência. Os resultados são, por vezes, contraditórios, o que pode ocorrer devido às diferentes definições das amostras.

Bevilaqua e Loyo (I998) examinam dados de 38 bancos entre o quarto trimestre de 1994 e o segundo trimestre de 1998 , período em que a participação de bancos estrangeiros aumentou no país, principalmente por meio da aquisição de bancos em reestruturação, e identificam ganhos de eficiência de custos na produção de serviços bancários, em conformidade com a hipótese da quiet life, que prevê que bancos domésticos, quando submetidos a um ambiente pouco competitivo, têm poucos incentivos para melhorar sua eficiência operacional.

Guimarães (2002) utiliza dados trimestrais de I995 a 200I e encontra resultados que sugerem crescimento da rentabilidade dos bancos domésticos em resposta ao aumento da participação de bancos estrangeiros. O autor não encontra efeito em relação a custos administrativos, o que contradiz a hipótese da quiet life.

O estudo de Fachada (2008) documenta a evolução do capital estrangeiro no sistema bancário brasileiro pós-Plano Real e investiga os determinantes dos lucros e dos custos operacionais dos bancos. A amostra é composta de dados semestrais de 90 bancos comerciais privados desde 1996 até 2006. Os resultados indicam que a maior presença de bancos estrangeiros contribui para a redução dos custos administrativos dos bancos domésticos - em conformidade com a hipótese da quiet life, mas não para a redução da lucratividade.

Coutinho e Amaral (20I0) utilizam a técnica da análise de fronteira estocástica para identificar se os bancos com controle estrangeiro são mais eficientes 
do que os bancos nacionais. Foram analisados dados de 70 bancos, sendo I7 estrangeiros, 4I privados nacionais e I2 públicos, entre 200I e 2005. Os resultados indicam que o desempenho dos bancos estrangeiros na eficiência de lucros é maior que a dos bancos nacionais; porém, na fronteira custo, o desempenho dos estrangeiros não foi sistematicamente superior ao dos nacionais, assim como não há evidências de progresso técnico na atividade bancária no Brasil.

Finalmente, o estudo de Teles (20II) analisa os efeitos da abertura do sistema bancário brasileiro com base em dados referentes a I 8 bancos nacionais com carteira comercial entre I997 e 2007. A autora identifica que há aumento da lucratividade e não há redução dos custos desses bancos, refutando a hipótese da quiet life. Teles (20II) encontra também uma redução dos custos dos bancos maiores, indicando economias de escala e escopo.

Diferentemente dos trabalhos citados, este estudo não aborda a questão dos bancos estrangeiros no Brasil sob a ótica da rentabilidade e da eficiência, e, sim, enfoca a atuação desses bancos nos mercados de créditos livres e de derivativos cambiais. Além disso, o período amostral inclui uma crise financeira com origem no exterior, o que permite a identificação de possíveis diferenças na reação dos bancos por tipo de controle.

\section{DADOS E AMOSTRA}

A amostra é composta por dados de bancos comerciais, bancos de investimento e bancos múltiplos com carteira comercial ou de investimento, desde 2005 até 20II. A restrição do período amostral visa permitir analisar períodos relativamente homogêneos antes e depois da crise de 2008/2009. Foram incluídos todos os bancos em atividade em cada período.

Nos casos em que os bancos pertencem a um mesmo conglomerado financeiro, utilizam-se as informações no nível conglomerado, de acordo com Gatev e Strahan (2006) e Kashyap, Rajan e Stein (2002). Por simplicidade, cada unidade observacional é chamada de banco.

\subsection{VISÃO GERAL}

A Tabela I apresenta os valores (em $\mathrm{R} \$$ bilhões) do somatório dos ativos dos bancos, segregados em esferas de controle, nas datas-base de 3I de dezembro desde 2005 até 20II. Durante o período amostral, em média, de cada R $\$$ Ioo em ativos do sistema bancário, cerca de $\mathrm{R} \$ 45$ eram ativos de bancos privados nacionais, $\mathrm{R} \$ 33$ de bancos públicos e $\mathrm{R} \$ 23$ de bancos de controle estrangeiro. 
TABELA I

VISÃO GERAL DA COMPOSIÇÃO DO SISTEMA BANCÁRIO

\begin{tabular}{|c|c|c|c|c|c|c|c|c|}
\hline & \multicolumn{2}{|c|}{ ESTRANGEIROS } & \multicolumn{2}{|c|}{ PRIVADOS NACIONAIS } & \multicolumn{2}{|c|}{ PÚBLICOS } & \multicolumn{2}{|c|}{ TOTAL } \\
\hline & VALOR ATIVO & $\%$ & VALOR ATIVO & $\%$ & VALOR ATIVO & $\%$ & VALOR ATIVO & $\%$ \\
\hline Dez./05 & 347 & $24 \%$ & 596 & $42 \%$ & 488 & $34 \%$ & 1.431 & $100 \%$ \\
\hline Dez./06 & 413 & $24 \%$ & 751 & $44 \%$ & 555 & $32 \%$ & 1.719 & $100 \%$ \\
\hline Dez./07 & 534 & $24 \%$ & 1.016 & $46 \%$ & 669 & $30 \%$ & 2.218 & $100 \%$ \\
\hline Dez./08 & 686 & $24 \%$ & 1.329 & $46 \%$ & 870 & $30 \%$ & 2.885 & $100 \%$ \\
\hline Dez./09 & 658 & $21 \%$ & 1.363 & $44 \%$ & 1.070 & $35 \%$ & 3.091 & $100 \%$ \\
\hline Dez./10 & 784 & $21 \%$ & 1.689 & $46 \%$ & 1.216 & $33 \%$ & 3.689 & $100 \%$ \\
\hline Dez./11 & 904 & $21 \%$ & 1.949 & $45 \%$ & 1.491 & $34 \%$ & 4.344 & $100 \%$ \\
\hline
\end{tabular}

Valor dos ativos em R\$ bilhões.

Fonte: Banco Central do Brasil.

\subsection{CONCESSÕES DE CRÉDITOS LIVRES REFERENCIAIS PARA TAXA DE JUROS}

A base de dados inclui os volumes diários concedidos em operações de crédito livres referenciais para taxa de juros ${ }^{3}$ por cada banco do Sistema Financeiro Nacional (SFN), no período de $\mathrm{I}^{\circ}$ de janeiro de 2005 a 3I de dezembro de $201 \mathrm{I}$.

Os créditos livres referenciais para taxa de juros representam, em média, $82 \%$ do total dos créditos com recursos livres e $52 \%$ do total dos créditos do SFN.

Essas operações podem ser feitas em diferentes modalidades. No caso de pessoas jurídicas, as modalidades são: hot money, desconto de duplicatas, desconto de notas promissórias, capital de giro, conta garantida, financiamento imobiliário, aquisição de bens, vendor, adiantamentos sobre contratos de câmbio (ACC), export notes e repasses de empréstimos externos. Dentre elas, capital de giro representa, em média, mais da metade do volume total. As duas modalidades seguintes mais importantes são conta garantida e ACC. Somadas, essas três modalidades representam, em média, mais de $75 \%$ do volume total de operações referenciais para taxas de juros a pessoas jurídicas.

Recursos livres identificados pela Circular n².957, de 30 de dezembro de I999. Recuperado em 30 dezembro, I999, de http://www.bcb.gov.br. 
No caso de pessoas físicas, as modalidades são: cheque especial, crédito pessoal, financiamento imobiliário, aquisição de bens - veículos automotores -, aquisiç̧ão de bens - outros bens -, oriundas de cartão de crédito e outras. Dessas, crédito pessoal representa, em média, pouco menos da metade do volume total. A segunda modalidade mais importante é aquisição de bens - veículos automotores. Somadas, essas duas modalidades representam, em média, mais de $80 \%$ do volume total de operações referenciais para taxas de juros a pessoas físicas.

A Tabela 2 caracteriza os dados por esfera de controle, em termos dos valores concedidos anualmente e da quantidade de bancos que atuaram nesse mercado em cada ano. A quantidade de bancos varia não apenas por possíveis entradas de novas instituições, fusões, aquisições etc., mas também porque algum banco pode ter deixado de fazer operações de crédito em algum período.

Nota-se na Tabela 2 que, durante o período amostral, em média, de cada $\mathrm{R} \$$ Ioo concedidos por bancos, cerca de $\mathrm{R} \$ 50$ foram concedidos por aqueles de controle privado nacional, $\mathrm{R} \$ 26$ por bancos de controle estrangeiro e $\mathrm{R} \$ 24$ por bancos públicos. A tabela também permite observar que as concessões de cada ano são superiores às do ano anterior, à exceção de 2009. Nesse ano, houve uma redução do total concedido, devido à redução das concessões dos bancos estrangeiros e privados nacionais, em razão da crise internacional de 2008/2009.

\section{TABELA 2}

QUANTIDADE DE BANCOS E VALORES DAS CONCESSÕES ANUAIS DE CRÉDITOS LIVRES REFERENCIAIS PARA TAXA DE JUROS

\begin{tabular}{|c|c|c|c|c|c|c|c|c|c|c|c|c|}
\hline & \multicolumn{3}{|c|}{ ESTRANGEIROS } & \multicolumn{3}{|c|}{ PRIVADOS NACIONAIS } & \multicolumn{3}{|c|}{ PÚBLICOS } & \multicolumn{3}{|c|}{ TOTAL AMOSTRA } \\
\hline & QTDE. & $\begin{array}{l}\text { VALOR } \\
\text { CONC. }\end{array}$ & $\begin{array}{c}\% \\
\text { CONC. }\end{array}$ & QTDE. & $\begin{array}{l}\text { VALOR } \\
\text { CONC. }\end{array}$ & $\begin{array}{c}\% \\
\text { CONC. }\end{array}$ & QTDE. & $\begin{array}{l}\text { VALOR } \\
\text { CONC. }\end{array}$ & $\begin{array}{c}\% \\
\text { CONC. }\end{array}$ & QTDE. & $\begin{array}{l}\text { VALOR } \\
\text { CONC. }\end{array}$ & $\begin{array}{c}\% \\
\text { CONC. }\end{array}$ \\
\hline 2005 & 44 & 357 & $27 \%$ & 64 & 633 & $48 \%$ & 13 & 318 & $24 \%$ & 121 & 1.309 & $100 \%$ \\
\hline 2006 & 46 & 389 & $27 \%$ & 63 & 700 & $49 \%$ & 12 & 339 & $24 \%$ & 121 & 1.428 & $100 \%$ \\
\hline 2007 & 47 & 428 & $26 \%$ & 62 & 809 & $50 \%$ & 12 & 378 & $23 \%$ & 121 & 1.615 & $100 \%$ \\
\hline 2008 & 49 & 471 & $26 \%$ & 62 & 907 & $50 \%$ & 12 & 428 & $24 \%$ & 123 & 1.806 & $100 \%$ \\
\hline 2009 & 51 & 442 & $25 \%$ & 62 & 875 & $49 \%$ & 10 & 455 & $26 \%$ & 123 & 1.772 & $100 \%$ \\
\hline 2010 & 49 & 484 & $24 \%$ & 62 & 1.036 & $52 \%$ & 9 & 489 & $24 \%$ & 120 & 2.009 & $100 \%$ \\
\hline 2011 & 50 & 556 & $25 \%$ & 60 & 1.123 & $51 \%$ & 9 & 507 & $23 \%$ & 119 & 2.187 & $100 \%$ \\
\hline
\end{tabular}

Valor das concessões em R\$ bilhões. 


\subsection{TAXAS DE JUROS DAS OPERAÇÕES DE CRÉDITOS LIVRES REFERENCIAIS}

A base de dados inclui as taxas médias mensais das principais modalidades de operação de crédito praticadas por cada banco do SFN, no período de $\mathrm{I}^{\circ}$ de janeiro de 2005 a 3I de dezembro de 20 II. A análise restringe-se às modalidades mais representativas em termos de volume. Dentre as operações de crédito à pessoa física, os empréstimos pessoais e o crédito para veículos representaram, respectivamente, $48 \%$ e $34 \%$ do saldo de operações em 20 II. No crédito à pessoa jurídica, as modalidades mais representativas são as operações de capital de giro ( $57 \%$ do saldo), conta garantida (I2\%) e ACC (7\%).

\section{TABELA 3}

TAXAS DE JUROS MEDIAS PRATICADAS NAS MODALIDADES SELECIONADAS DE CRÉDITO A PESSOA JURÍDICA

\begin{tabular}{|c|ccc|ccc|ccc}
\hline & \multicolumn{2}{|c}{ CAPITAL DE GIRO } & \multicolumn{2}{c|}{ CONTA GARANTIDA } & \multicolumn{3}{c}{ ACC } \\
\hline \multirow{2}{*}{ ESTRANG. } & $\begin{array}{l}\text { PRIV. } \\
\text { NAC. }\end{array}$ & PÚBLICO & ESTRANG. & $\begin{array}{l}\text { PRIV. } \\
\text { NAC. }\end{array}$ & PÚBLICO & ESTRANG. & $\begin{array}{c}\text { PRIV. } \\
\text { NAC. }\end{array}$ & PÚBLICO \\
\hline 2005 & 23,6 & 29,2 & 31,7 & 29,9 & 39,1 & 71,5 & 5,0 & 8,3 & 5,6 \\
\hline 2006 & 19,3 & 27,6 & 30,7 & 27,6 & 35,7 & 70,5 & 6,5 & 8,5 & 7,8 \\
\hline 2007 & 15,2 & 24,3 & 24,7 & 23,9 & 30,0 & 65,3 & 6,7 & 7,5 & 8,7 \\
\hline 2008 & 16,1 & 24,4 & 22,4 & 24,7 & 32,5 & 63,2 & 6,8 & 9,2 & 9,5 \\
\hline 2009 & 14,6 & 23,3 & 20,7 & 22,8 & 36,0 & 32,8 & 6,4 & 7,7 & 9,4 \\
\hline 2010 & 13,1 & 20,8 & 20,1 & 20,4 & 36,7 & 30,7 & 4,0 & 6,9 & 7,0 \\
\hline 2011 & 12,9 & 21,9 & 21,2 & 25,1 & 51,5 & 31,3 & 3,9 & 6,5 & 6,8 \\
\hline Total & $\mathbf{1 6 , 4}$ & $\mathbf{2 4 , 5}$ & $\mathbf{2 4 , 6}$ & $\mathbf{2 5 , 0}$ & $\mathbf{3 7 , 4}$ & $\mathbf{5 2 , 4}$ & $\mathbf{5 , 6}$ & $\mathbf{7 , 8}$ & $\mathbf{7 , 8}$ \\
\hline
\end{tabular}

Taxas em \% a.a.

Fonte: Banco Central do Brasil.

As tabelas 3 e 4 mostram as taxas médias praticadas em cada modalidade selecionada por esfera de controle. Nota-se, na Tabela 3, que os bancos estrangeiros praticam, em média, taxas menores do que as dos demais nas operações de crédito a pessoas jurídicas. Já no crédito à pessoa física (Tabela 4), os bancos 
públicos praticam taxas menores que as dos demais na modalidade crédito pessoal. Na modalidade de empréstimo para aquisição de veículos, os bancos públicos e estrangeiros se alternam ao longo do tempo no oferecimento da menor taxa média.

\section{TABELA 4}

TAXAS DE JUROS MÉDIAS PRATICADAS NAS MODALIDADES SELECIONADAS DE CRÉDITO A PESSOA FÍSICA

\begin{tabular}{|c|ccc|ccc}
\hline & \multicolumn{3}{|c|}{ CRÉDITO PESSOAL } & \multicolumn{3}{c}{ FINANCIAMENTO DE VEICULOS } \\
\hline & ESTRANG. & $\begin{array}{c}\text { PRIV. } \\
\text { NACIONAL }\end{array}$ & PÚBLICO & ESTRANG. & $\begin{array}{c}\text { PRIV. } \\
\text { NACIONAL }\end{array}$ & PÚBLICO \\
\hline 2005 & 71,7 & 87,9 & 56,2 & 33,8 & 32,9 & 41,6 \\
\hline 2006 & 60,8 & 73,2 & 52,0 & 28,1 & 33,0 & 29,7 \\
\hline 2007 & 54,9 & 50,5 & 43,0 & 24,4 & 29,1 & 24,0 \\
\hline 2008 & 58,8 & 67,3 & 42,4 & 25,5 & 31,0 & 24,8 \\
\hline 2009 & 57,7 & 49,9 & 34,2 & 23,0 & 27,0 & 22,1 \\
\hline 2010 & 50,0 & 39,8 & 34,6 & 20,3 & 24,2 & 20,7 \\
\hline 2011 & 55,6 & 44,6 & 40,3 & 23,4 & 28,7 & 23,5 \\
\hline Total & $\mathbf{5 8 , 6}$ & $\mathbf{5 9 , 3}$ & $\mathbf{4 3 , 3}$ & $\mathbf{2 5 , 6}$ & $\mathbf{2 9 , 5}$ & $\mathbf{2 6 , 7}$ \\
\hline
\end{tabular}

Taxas em \% a.a.

Fonte: Banco Central do Brasil.

\subsection{MERCADO DE DERIVATIVOS CAMBIAIS}

Para os derivativos cambiais, são utilizados dados mensais de operações com esses contratos registrados na Cetip S. A. - Mercados Organizados - e na Bolsa de Valores, Mercadorias e Futuros (BM\&FBovespa). As informações incluem: tipo de contrato, tipo de contraparte (instituição financeira, investidor institucional ou contraparte não financeira) para as operações de balcão, tipo de moeda, valor nocional na moeda estrangeira e em reais, e posição (comprada ou vendida).

A data a partir da qual existe informação varia de acordo com o tipo de contrato: I. desde janeiro de 2005 para os contratos registrados na BM\&FBovespa 
(futuros, opções padronizadas, opções flexíveis e swaps) ${ }^{4}$; 2. desde janeiro de 2006 para os contratos de swap com registro na Cetip; 3 . desde março de 2008 para os contratos a termo de moeda (non-deliverable forwards - NDF) com registro na Cetip.

O foco deste trabalho é identificar o papel dos bancos estrangeiros em prover esse tipo de tecnologia de gestão de risco para o setor não financeiro e para o próprio setor financeiro, não tendo o objetivo de avaliar as implicações do uso de derivativos cambiais na exposição ao risco de mercado das partes contratantes. Dessa maneira, não é de interesse estimar o tamanho ou a direção (comprada ou vendida) das exposições cambiais dos bancos. Assim, salvo menção expressa em contrário, a análise tratará indistintamente posições compradas e vendidas.

As variáveis de interesse são os volumes negociados (valores nocionais) dos contratos derivativos, que servem como indicadores da capacidade de atender a demandas de cada um dos setores discriminados (setor não financeiro, investidores institucionais e o próprio setor financeiro). No caso de contratos entre duas instituições financeiras - uma na posição comprada e outra na vendida -, o volume do contrato será contado duas vezes, uma vez que não há distinção de posições. Entretanto, entende-se que essa questão não é fonte de viés para nenhuma das análises conduzidas no trabalho.

A Tabela 5 apresenta os valores nocionais dos contratos derivativos (em USD bilhões) contratados anualmente e a quantidade de bancos que atuaram nesse mercado em cada ano. Assim como nos dados do mercado de crédito, a quantidade de bancos varia não apenas por causa de possíveis entradas de novas instituições, fusões, aquisições etc., mas também porque a amostra inclui, a cada período, apenas (e todos) os bancos que realizaram operações com derivativos cambiais. Nota-se que o volume total de derivativos cambiais praticamente dobra de 2006 para 2008 , reduzindo-se em relação a 2008 no período pós-crise. Os bancos estrangeiros detêm mais da metade do mercado em todos os anos, com exceção de 2010 , e os bancos públicos têm tido participação crescente, embora ainda pequena, se comparados aos bancos das demais esferas de controle.

4 Os contratos futuros e as opções padronizadas são produtos de bolsa. Dessa forma, a BM\&F assume a figura de contraparte central nesses contratos. Os swaps e as opções flexíveis registrados na BM\&F são contratos de balcão, permitindo a identificação da contraparte. 
TABELA 5

QUANTIDADE DE BANCOS E VALORES NOCIONAIS DOS

DERIVATIVOS CAMBIAIS POR ESFERA DE CONTROLE

\begin{tabular}{|c|c|c|c|c|c|c|c|c|c|c|c|c|}
\hline & \multicolumn{3}{|c|}{ ESTRANGEIROS } & \multicolumn{3}{|c|}{ PRIVADOS NACIONAIS } & \multicolumn{3}{|c|}{ PÚBLICOS } & \multicolumn{3}{|c|}{ TOTAL AMOSTRA } \\
\hline & QTDE. & $\begin{array}{l}\text { VALOR } \\
\text { DERIV. }\end{array}$ & $\begin{array}{c}\% \\
\text { DERIV. }\end{array}$ & QTDE. & $\begin{array}{l}\text { VALOR } \\
\text { DERIV. }\end{array}$ & $\begin{array}{c}\% \\
\text { DERIV. }\end{array}$ & QTDE. & $\begin{array}{l}\text { VALOR } \\
\text { DERIV. }\end{array}$ & $\begin{array}{c}\% \\
\text { DERIV. }\end{array}$ & QTDE. & $\begin{array}{l}\text { VALOR } \\
\text { DERIV. }\end{array}$ & $\begin{array}{c}\% \\
\text { DERIV. }\end{array}$ \\
\hline 2006 & 39 & 2,324 & $54 \%$ & 40 & 1,928 & $45 \%$ & 3 & 27 & $1 \%$ & 82 & 4,279 & $100 \%$ \\
\hline 2007 & 36 & 4,057 & $55 \%$ & 40 & 3,325 & $45 \%$ & 3 & 34 & $0 \%$ & 79 & 7,416 & $100 \%$ \\
\hline 2008 & 36 & 4,471 & $53 \%$ & 38 & 3,921 & $46 \%$ & 5 & 78 & $1 \%$ & 79 & 8,470 & $100 \%$ \\
\hline 2009 & 37 & 3,729 & $57 \%$ & 37 & 2,726 & $41 \%$ & 3 & 135 & $2 \%$ & 77 & 6,590 & $100 \%$ \\
\hline 2010 & 37 & 3,292 & $46 \%$ & 40 & 3,508 & $49 \%$ & 4 & 288 & $4 \%$ & 81 & 7,088 & $100 \%$ \\
\hline 2011 & 35 & 3,425 & $51 \%$ & 40 & 3,047 & $45 \%$ & 3 & 260 & $4 \%$ & 78 & 6,732 & $100 \%$ \\
\hline
\end{tabular}

Valor nocional em USD bilhões.

Fonte: Banco Central do Brasil.

\section{METODOLOGIA}

O propósito principal deste artigo - conforme mencionado anteriormente - é realizar uma análise descritiva agregada dos mercados de crédito e de derivativos cambiais, de modo a avaliar se bancos estrangeiros responderam de forma diferente aos impactos da crise financeira de 2008/2009. Para documentar como a atuação nesses mercados variou em períodos de crise em função do tipo de controle acionário, adotou-se uma metodologia fundamentada principalmente na análise gráfica.

De modo complementar, utilizou-se a técnica de regressões lineares para estimar variações nas médias das variáveis de interesse nos três períodos analisados: antes da crise, crise e pós-crise. O objetivo dessas regressões é estimar médias nos diferentes períodos e testar se essas médias são diferentes estatisticamente entre si. Portanto, como os modelos empregados não se propõem a inferências de causalidade, não se faz uma discussão sobre hipóteses de identificaçãos. Outra

Como não se trata de um teste econométrico para estimar parâmetros de um modelo teórico ou testar uma forma reduzida fundamentada num quase experimento, não há preocupações com forma funcional ou com potencial viés na estimação dos parâmetros. 
maneira de apresentar a informação seria por meio de estatística descritiva, mas o procedimento escolhido tem a vantagem de permitir tratar a heteroscedasticidade ${ }^{6}$.

São descritas a seguir as regressões utilizadas para estimar essas variações para participação no mercado de crédito livre, taxas de juros de crédito livre e participação no mercado de swaps cambiais.

\subsection{PARTICIPAÇÃO NO MERCADO DE CRÉDITO LIVRE}

Para identificar possíveis alterações na configuração do mercado durante e após a crise, o seguinte modelo foi estimado para cada um dos três conjuntos de bancos com a participação de mercado como variável dependente e indicadores de crise e pós-crise como variáveis independentes:

$$
\text { ParticMercadoCredito }_{t}=\alpha+\beta \text { Crise }_{t}+\delta \text { PosCrise }_{t}+\varepsilon_{t}
$$

A variável participação no mercado de crédito é calculada da seguinte maneira: em cada período mensal $t$, somam-se as concessões de todos os bancos de determinada esfera de controle (estrangeiros, privados nacionais e públicos) e divide-se o resultado pelo total das concessões do SFN. A variável crise é uma dummy que assume valor I para o período de setembro/2008 a junho/2009, e zero nos demais. De acordo com Ait-Sahalia, Andritzky, Jobst, Nowak e Tamirisa (2012) e Brunnermeier (2009), de 2007 até a falência do banco Lehman Brothers nos Estados Unidos, em I4 de setembro de 2008 , a crise estava restrita à questão das hipotecas subprime e ainda não havia atingido os países emergentes. A variável pós-crise é uma dummy que assume valor I para o período de julho/2009 a dezembro/20II, e zero nos demais. $O$ termo de erro é representado por $\varepsilon_{\mathrm{t}}$.

O parâmetro $\beta$ (obtido para cada grupo de bancos) indica o efeito da crise sobre a participação de mercado de determinado grupo. A comparação entre o $\beta$ obtido para o grupo de bancos estrangeiros e os dos demais grupos (privado nacional e público) indica se os estrangeiros foram afetados diferentemente pela crise financeira ou não.

\section{TAXAS DE JUROS DE CRÉDITO LIVRE}

Para identificar possíveis alterações nas taxas praticadas pelos bancos estrangeiros relativamente aos demais durante e após a crise, estima-se o seguinte modelo para cada uma das modalidades de crédito selecionadas:

$$
\text { TaxaRelativa }_{t}=\alpha+\beta \text { Crise }_{t}+\delta \text { PosCrise }_{t}+\varepsilon_{t}
$$

Os testes de White e Breusch-Pagan foram aplicados para detectar heteroscedasticidade. Os resultados não são reportados, mas, em todas as regressões, os erros padrão são heteroscedásticos. 
A variável taxa relativa é calculada da seguinte maneira: em cada período mensal $t$, subtrai-se da taxa média praticada pelos bancos estrangeiros a taxa média praticada pelos bancos privados nacionais e públicos. As variáveis crise e pós-crise são dummies definidas na seção anterior. O termo de erro é representado por $\varepsilon_{\mathrm{t}}$.

\subsection{PARTICIPAÇÃO NO MERCADO DE SWAPS CAMBIAIS}

Seguindo o mesmo procedimento da análise feita para o mercado de crédito, para identificar possíveis alterações nas participações de mercado de swaps ${ }^{7}$ cambiais de cada conjunto de bancos, utiliza-se a seguinte regressão:

$$
\text { ParticMercadoDerivativo }_{t}=\alpha+\beta \text { Crise }_{t}+\delta \text { PosCrise }_{t}+\varepsilon_{t}
$$

A variável participação no mercado de derivativos é calculada da seguinte maneira: em cada período $t$ (mês), somam-se os valores nocionais de todos os bancos de cada conjunto (estrangeiros, privados nacionais e públicos) e divide-se tal número pelo total obtido pela soma dos valores dos três conjuntos. As dummies de crise e pós-crise e o termo $\varepsilon_{\mathrm{t}}$ são definidas como na seção 4.I.

\section{BANCOS ESTRANGEIROS E CONCESSÃO DE CRÉdITO}

A crise financeira internacional de 2008/2009 expôs a suscetibilidade do crédito nos países emergentes a choques externos. Montoro e Rojas-Suarez (20I2) mostram que os países do Leste Europeu foram os mais afetados pela redução do crédito bancário, seguidos dos países da América Latina e da Ásia. Para países da América Latina, Montoro e Rojas-Suarez (20I2) apontam que os bancos estrangeiros proveram menos crédito que os bancos domésticos durante a crise, mesmo controlando por outros fatores como tamanho, capitalização, liquidez, eficiência e rentabilidade. Cetorelli e Goldberg (20II) relacionam esse fenômeno à ativação de um canal interno de mercado de capitais, em que os bancos com atuação global transferem recursos de suas afiliadas estrangeiras para a sede.

Nesta seção, procura-se caracterizar o comportamento dos bancos de controle estrangeiro no Brasil, com foco na crise de 2008/2009. Especificamente,

A análise limita-se aos swaps, pois a bolsa assume a figura de contraparte central dos contratos futuros, e, para os contratos a termo, os dados estão disponíveis apenas a partir de março de 2008 , o que faz com que o número de observações não seja suficiente para análise. 
analisam-se informações de concessões de créditos livres antes, durante e depois da crise de 2008, buscando identificar possíveis diferenças de comportamento dos bancos estrangeiros em comparação com os nacionais.

\subsection{VOLUMES DE CONCESSÕES DE BANCOS ESTRANGEIROS E CRISE FINANCEIRA INTERNACIONAL}

Annibal, Lundberg e Koyama (2009) apresentam de forma detalhada os impactos da crise financeira internacional de 2008/2009 sobre o mercado de crédito brasileiro. Em relação às operações de crédito com recursos livres, Annibal et al. (2009) mostram que aquelas destinadas a pessoas jurídicas foram as mais afetadas pela crise, especialmente as operações de conta garantida, aquisição de bens e vendor. Adicionalmente, os autores ponderam que a redução dos volumes de concessão de créditos livres durante a crise pode ser mais bem explicada pela maior aversão ao risco dos bancos do que por uma escassez de fontes domésticas de financiamento, uma vez que as captações de depósitos por bancos públicos e privados aumentaram no período.

A Tabela 6 mostra os resultados das estimações da Equação (I) para os três conjuntos de bancos. Observa-se uma redução de 2,2 pontos percentuais (p.p.), estatisticamente significante no nível de ı\%, na média mensal de participação dos bancos estrangeiros no período pós-crise em relação ao período pré-crise. A queda de participação dos bancos estrangeiros teve como contrapartida um aumento, principalmente, dos bancos privados nacionais (I,6 p.p.). Esse resultado indica que os bancos estrangeiros reduziram sua participação no período de crise, o que sugere uma possível transmissão do choque negativo de liquidez ocorrido nos países desenvolvidos.

TABELA 6

PARTICIPAÇÕES DE MERCADO EM OPERAÇÕES DE CRÉDITO REFERENCIAIS PARA TAXA DE JUROS

\begin{tabular}{lccc}
\hline & ESTRANGEIROS & PÚBLICOS & PRIVADOS NACIONAIS \\
\hline \multirow{2}{*}{ Crise } & $-0,006$ & $0,008^{*}$ & $-0,002$ \\
\cline { 2 - 4 } & $(-1,64)$ & $(1,66)$ & $(-0,39)$ \\
\hline \multirow{2}{*}{ Pós-crise } & $-0,022^{* * *}$ & $0,006^{*}$ & $0,016^{* * *}$ \\
& $(-8,91)$ & $(1,94)$ & $(5,16)$ \\
\hline
\end{tabular}

(continua) 


\section{TABELA 6 (CONClusão)}

PARTICIPAÇÖES DE MERCADO EM OPERAÇÖES DE CRẼITO REFERENCIAIS PARA TAXA DE JUROS

\begin{tabular}{lccc}
\hline & ESTRANGEIROS & PÚBLICOS & PRIVADOS NACIONAIS \\
\hline Constante & 0,268 & 0,238 & 0,494 \\
\cline { 2 - 4 } & $(163,71)$ & $(164,70)$ & $(267,28)$ \\
\hline$R^{2}$ & 0,510 & 0,067 & 0,279 \\
\hline Observações & 84 & 84 & 84 \\
\hline
\end{tabular}

Estatísticas $t$ robustas à heteroscedasticidade estão entre parênteses; * *** e *** indicam significância estatística para os níveis ı०\%, 5\% е ı\%.

Fonte: Elaborada pelos autores com base em dados do Banco Central do Brasil.

Para comparar, ao longo do tempo, o comportamento dos diferentes tipos de bancos eliminando a influência do tamanho dos ativos e, ao mesmo tempo, da proporção da carteira de crédito em relação aos ativos, apresentam-se, no Gráfico I, os valores das concessões de crédito trimestrais normalizados em Ioo no início do período amostral.

\section{GRÁFICO I}

VOLUME DE CONCESSÕES DE CREDITO (CONCESSÕES NO IT/2005=I00)

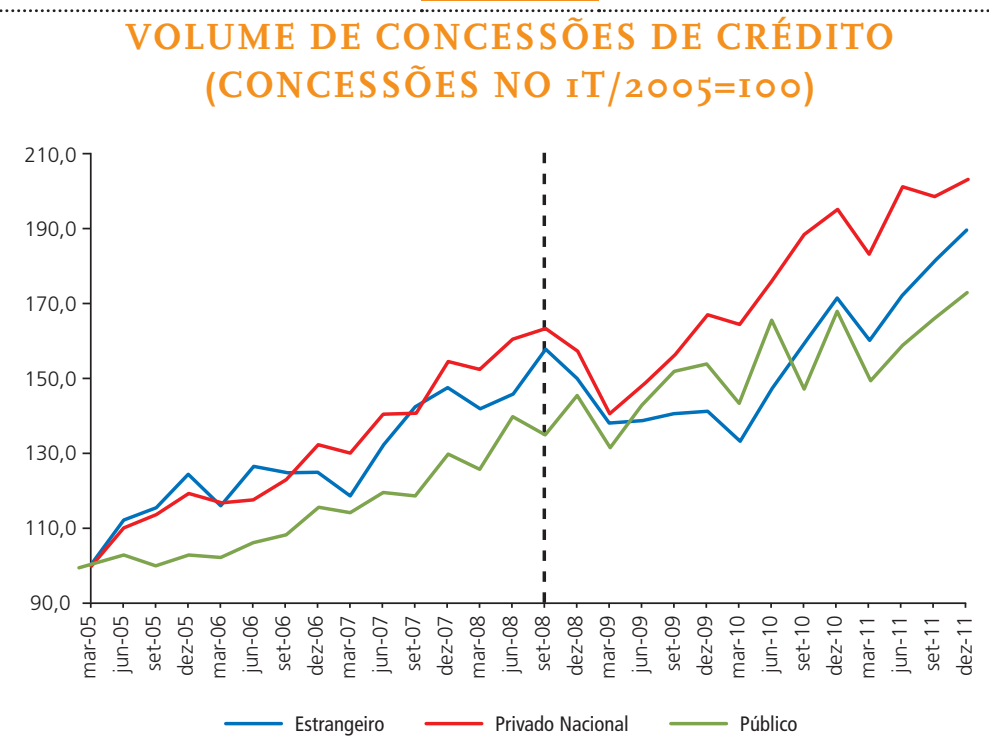

Fonte: Elaborado pelos autores com base em dados do Banco Central do Brasil. 
No Gráfico I, pode-se notar crescimento significativo do volume de crédito concedido. Os bancos privados nacionais e estrangeiros reduziram suas concessões de crédito na crise, enquanto os públicos tiveram crescimento positivo das concessões praticamente em todo o período desde o início da crise ${ }^{8}$. O retorno ao nível de concessões pré-crise ocorreu pouco mais de um ano depois, no quarto trimestre de 2009, no caso dos bancos privados nacionais, e dois anos depois, no terceiro trimestre de 20I0, no caso dos estrangeiros. Contudo, a partir daí e até o final de 20II, as concessões dos estrangeiros cresceram mais acentuadamente do que as dos demais grupos. Ao final do período amostral, o crescimento das concessões em relação ao primeiro trimestre de 2005 foi maior nos bancos privados nacionais, seguidos dos estrangeiros e, por último, dos públicos.

Essas observações indicam que, apesar de os bancos estrangeiros terem, em média, reduzido sua participação no mercado de créditos no período pós-crise, há indícios de alterações no comportamento desses bancos ao longo desse período. Esses resultados não são enviesados por reorganizações do sistema financeiro nacional, pois não houve alteração da esfera de controle nas maiores operações de fusões e aquisições no período amostral, detalhadas na seção 6 .

O Gráfico 2 apresenta a evolução da taxa de crescimento do volume concedido em um trimestre, em relação ao mesmo trimestre do ano anterior nos últimos cinco anos. Essa taxa de crescimento prescinde de um filtro para dessazonalizar a série temporal.

Pode-se notar uma queda substancial da taxa de crescimento das concessões no quarto trimestre de 2008 , em relação ao mesmo trimestre de 2007 , com taxas de crescimento negativas no primeiro trimestre de 2009. Os bancos privados nacionais só voltam a apresentar taxas positivas de crescimento do crédito no último trimestre de 2009 . Para os bancos estrangeiros, isso ocorre apenas no segundo trimestre de 20I0. Porém, deve-se lembrar que os valores de 2010 referem-se às taxas de crescimento em relação a 2009, já bastante comprimidas por causa da crise.

Nota-se também um arrefecimento da velocidade do crescimento das concessões feitas pelos bancos domésticos em meados de 2010 , possivelmente relacionado à reversão de medidas anticrise, que haviam reduzido os recolhimentos compulsórios das instituições financeiras ${ }^{9}$.

8 Apenas no primeiro trimestre de 2009 , as concessões dos bancos de controle público caíram aproximadamente $2,5 \%$ em relação às concessões do $3^{\circ}$ trimestre de 2008 .

9 O "Relatório de estabilidade financeira" de setembro de 20 Io detalha as alterações feitas (Banco Central do Brasil, 20Iо). 


\section{GRÁFICO 2}

TAXA DE CRESCIMENTO DAS CONCESSÖES DE CREDITO ${ }^{1 /}$ EM RELAÇÃO AO MESMO TRIMESTRE DO ANO ANTERIOR

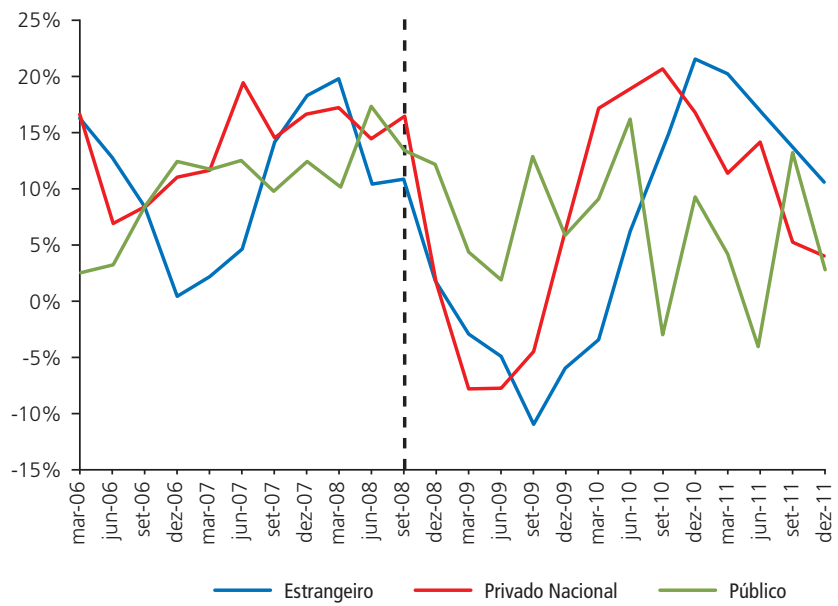

${ }^{\text {I/ }}$ Créditos livres referenciais para taxas de juros.

Fonte: Elaborado pelos autores com base em dados do Banco Central do Brasil.

A partir do último trimestre de 20Io, os bancos estrangeiros passam a ter as taxas de crescimento mais altas. Contudo, em 20II, a velocidade do crescimento das concessões para esses bancos também arrefece, possivelmente devido às medidas macroprudenciais adotadas pelo Banco Central do Brasil ${ }^{10}$. De acordo com o "Relatório de estabilidade financeira" (Banco do Central do Brasil, 20II), as medidas macroprudenciais implementadas em dezembro de 20 Io conseguiram moderar a expansão do crédito no país.

É possível supor que o comportamento diferente de cada conjunto de bancos não esteja relacionado à origem de seu capital controlador, mas, sim, ao porte médio dos bancos. Dawid e Takeda (20II) encontram evidências de que as medidas macroprudenciais de recomposição dos recolhimentos compulsórios impactaram especialmente as concessões de crédito para pessoas físicas dos bancos de menor porte. Em 2010 e 2OII, o percentual de concessões feitas por bancos de grande porte ${ }^{\text {II }}$ do conjunto de estrangeiros foi, em média, $73 \%$. O percentual de concessões feitas por bancos de grande porte é maior nos demais

10 Circulares $n^{\circ} 3.513,3.514$ e 3.5 I5, de 3 de dezembro de 2010 . Recuperado de www.bcb.gov.br.

II Os bancos de grande porte são aqueles cuja participação relativa no total do ativo total ajustado deduzido da parcela financiada da carteira própria excede $15 \%$. 
conjuntos: em média, $79 \%$ do total de concessões dos bancos de controle privado nacional e $88 \%$ do total de concessões dos bancos de controle público.

Desse modo, para verificar a robustez dos resultados, estima-se novamente o modelo (I) para cada conjunto de bancos, porém apenas com os bancos de grande porte. A variável participação no mercado de crédito passa a ser calculada da seguinte maneira: em cada período $t$, somam-se as concessões de todos os bancos de grande porte de determinada esfera de controle (estrangeiros, privados nacionais e públicos) e divide-se o resultado pelo total das concessões dos bancos de grande porte.

A Tabela 7 mostra os resultados das estimações para os três conjuntos de bancos. As inferências em relação ao período pós-crise mantêm-se inalteradas em relação às anteriores. A principal diferença é que se nota uma transferência da participação de mercado dos grandes estrangeiros para os grandes bancos de controle privado nacional durante a crise.

\section{TABELA 7}

\section{PARTICIPAÇÕES DE MERCADO EM CRÉDITOS LIVRES} REFERENCIAIS PARA TAXA DE JUROS BANCOS DE GRANDE PORTE

\begin{tabular}{lccc}
\hline & $\begin{array}{c}\text { CONTROLE } \\
\text { ESTRANGEIRO }\end{array}$ & CONTROLE PÚBLICO & $\begin{array}{c}\text { CONTROLE PRIVADO } \\
\text { NACIONAL }\end{array}$ \\
\hline Crise & $-0,019 * * *$ & 0,001 & $0,018 * * *$ \\
\hline & $(-5,78)$ & $(0,07)$ & $(3,47)$ \\
\hline Pós-crise & $-0,020^{* * *}$ & $0,005^{*}$ & $0,015 * * *$ \\
\hline Constante & $(-7,85)$ & $(1,33)$ & $(5,47)$ \\
\hline R $^{2}$ & $0,242 * * *$ & $0,264 * * *$ & $0,493 * * *$ \\
\hline Observações & $(180,31)$ & $(140,89)$ & $(286,66)$ \\
\hline
\end{tabular}

Estatísticas $t$ robustas à heteroscedasticidade estão entre parênteses; * *** e *** indicam significância estatística para os níveis ı०\%, 5\% e I\%.

Fonte: Elaborada pelos autores com base em dados do Banco Central do Brasil. 


\subsection{TAXAS DE JUROS E CRISE FINANCEIRA INTERNACIONAL}

Os gráficos 3 e 4 mostram as taxas de juros médias nas modalidades capital de giro e empréstimo pessoal ao longo do período amostral. Conforme dito na seção 3.2, essas modalidades correspondem a cerca da metade do total de créditos livres referenciais para taxas de juros para pessoas jurídicas e físicas, respectivamente.

\section{GRÁFICO 3}

\section{TAXA DE JUROS (\% A.A.) COBRADAS NAS OPERAÇÕES DE CAPITAL DE GIRO}

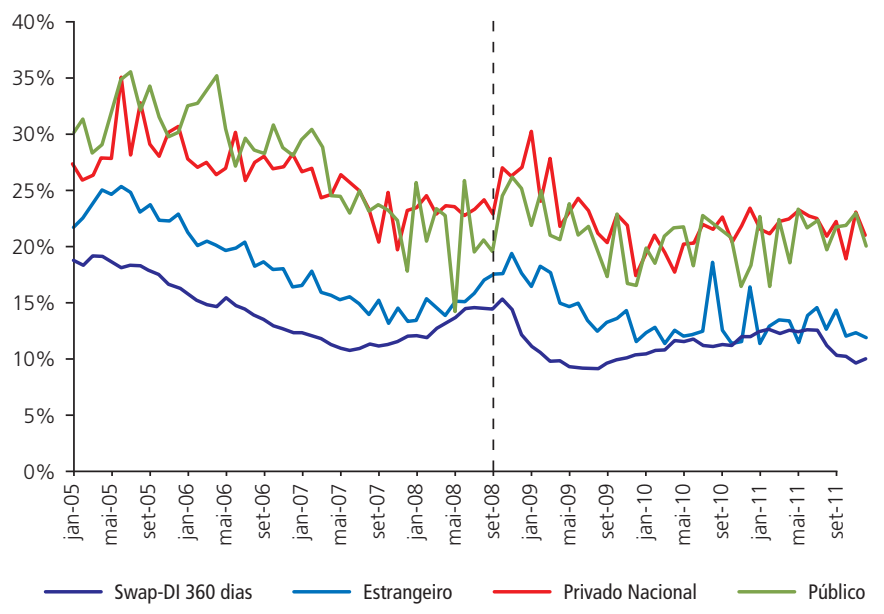

Fonte: Elaborado pelos autores com base em dados do Banco Central do Brasil.

O Gráfico 3 mostra que os bancos estrangeiros praticam, em média, taxas menores que os demais nas operações de capital de giro ao longo de praticamente todo o período amostral. Embora não seja objetivo do presente trabalho identificar as causas para esse fato, é possível que essas taxas menores estejam relacionadas ao fato de os bancos estrangeiros priorizarem operações com grandes empresas, com, supostamente, menor risco de crédito e assimetria informacional, conforme sugerido por Beck e Martinez Peria (2007).

O Gráfico 4 mostra que os bancos públicos são os que praticaram as menores taxas nas operações de empréstimo pessoal durante quase todo o período amostral. Na comparação entre bancos estrangeiros e privados nacionais, há uma alternância entre suas taxas médias para essa modalidade ao longo do tempo. 


\section{GRÁFICO 4}

\section{TAXA DE JUROS (\%A.A.) COBRADAS NAS}

OPERAÇÕES DE CRÉDITO PESSOAL

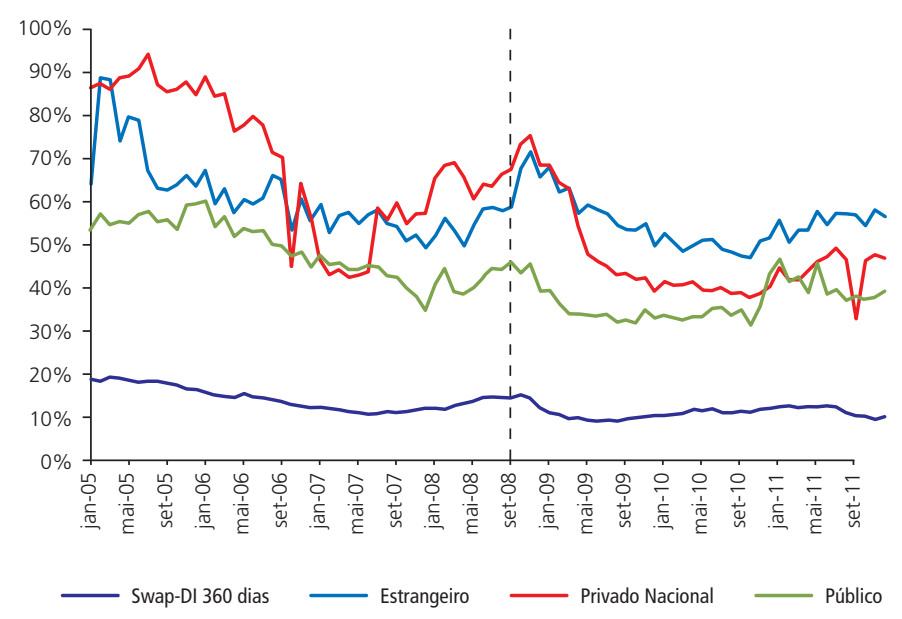

Fonte: Elaborado pelos autores com base em dados do Banco Central do Brasil.

Considerando que foram selecionadas para análise as cinco modalidades de crédito mais significativas (capital de giro, conta garantida, ACC, crédito pessoal e financiamento de veículos), são feitas dez estimações da Equação (2): em cada modalidade de crédito, os bancos estrangeiros são comparados aos bancos públicos e aos de controle privado nacional.

\section{TABELA 8}

DIFERENÇA ENTRE AS TAXAS DE JUROS ANUAIS PRATICADAS

PELOS BANCOS DE CONTROLE ESTRANGEIRO E DAS DUAS OUTRAS ESFERAS DE CONTROLE

\begin{tabular}{ccccccc}
\hline & \multicolumn{2}{c}{ CAPITAL DE GIRO } & \multicolumn{2}{c}{ CONTA GARANTIDA } & \multicolumn{2}{c}{ ACC } \\
\cline { 2 - 7 } & $\begin{array}{cccccc}\text { ESTR. }- \\
\text { PÚBL. }\end{array}$ & $\begin{array}{c}\text { ESTR. }- \\
\text { PRIV. }\end{array}$ & $\begin{array}{c}\text { ESTR. }- \\
\text { PÚBL. }\end{array}$ & $\begin{array}{c}\text { ESTR. }- \\
\text { PRIV. }\end{array}$ & $\begin{array}{c}\text { ESTR. }- \\
\text { PÚBL. }\end{array}$ & $\begin{array}{c}\text { ESTR. }- \\
\text { PRIV. }\end{array}$ \\
\hline \multirow{3}{*}{ Crise } & $3,05^{* * *}$ & $-0,84$ & $30,43 * * *$ & $-4,67 * * *$ & $-1,50 * * *$ & $1,67 * * *$ \\
\cline { 2 - 7 } & $(3,89)$ & $(-0,98)$ & $(7,24)$ & $(-5,43)$ & $(-4,50)$ & $(3,57)$ \\
\hline
\end{tabular}

(continua) 
TABELA 8 (CONCLUSÃo)

DIFERENÇA ENTRE AS TAXAS DE JUROS ANUAIS PRATICADAS PELOS BANCOS DE CONTROLE ESTRANGEIRO E DAS DUAS OUTRAS ESFERAS DE CONTROLE

\begin{tabular}{|c|c|c|c|c|c|c|}
\hline & \multicolumn{2}{|c|}{ CAPITAL DE GIRO } & \multicolumn{2}{|c|}{ CONTA GARANTIDA } & \multicolumn{2}{|c|}{$\mathrm{ACC}$} \\
\hline & $\begin{array}{l}\text { ESTR. - } \\
\text { PÚBL. }\end{array}$ & $\begin{array}{l}\text { ESTR. - } \\
\text { PRIV. }\end{array}$ & $\begin{array}{l}\text { ESTR. - } \\
\text { PÚBL. }\end{array}$ & $\begin{array}{l}\text { ESTR. - } \\
\text { PRIV. }\end{array}$ & $\begin{array}{l}\text { ESTR. - } \\
\text { PÚBL. }\end{array}$ & $\begin{array}{c}\text { ESTR. - } \\
\text { PRIV. }\end{array}$ \\
\hline \multirow{2}{*}{ Pós-crise } & $1,63 * *$ & $-0,55$ & $34,29 * * *$ & $-12,09 * * *$ & $-1,49 * * \star$ & $-0,51$ ** \\
\hline & $(2,4)$ & $(-1,13)$ & $(7,05)$ & $(-8,38)$ & $(-6,86)$ & $(-2,28)$ \\
\hline \multirow[t]{2}{*}{ Constante } & $-9,08 * * *$ & $-7,82 * * *$ & $-43,13^{* * *}$ & $-7,56 * * *$ & $-1,52 * * *$ & $-2,20 * * *$ \\
\hline & $(18,84)$ & $(21,14)$ & $(-79,59)$ & $(-23,18)$ & $(-9,73)$ & $(-12,08)$ \\
\hline$R^{2}$ & 0,127 & 0,021 & 0,905 & 0,569 & 0,388 & 0,274 \\
\hline Obs. & 84 & 84 & 84 & 84 & 84 & 84 \\
\hline
\end{tabular}

As colunas "Estr. - Públ." e "Estr. - Priv." referem-se às estimações em que se calculou a variável taxa relativa em relação aos bancos públicos e aos de controle privado nacional, respectivamente. Estatísticas $t$ robustas à heteroscedasticidade estão entre parênteses; $*$, $* *, e^{*} * *$ indicam significância estatística para os níveis I0\% 5\% e I\%.

Fonte: Elaborada pelos autores com base em dados do Banco Central do Brasil.

Os resultados das estimações da Equação (2) são mostrados nas tabelas 8 (modalidades relativas a crédito a pessoas jurídicas) e 9 (modalidades referentes a pessoas físicas). A Tabela 8 mostra que, para as operações de capital de giro, os bancos estrangeiros praticavam, antes da crise, taxa 9,08 p.p. inferior à praticada pelos públicos e 7,82 p.p. inferior à taxa média dos privados nacionais. A diferença para os bancos públicos diminuiu em I,63 p.p. durante a crise e 3,05 p.p. após a crise (relativamente ao período pré-crise), e a diferença em relação aos bancos privados nacionais nos períodos de crise e pós-crise não se alterou de maneira estatisticamente significante.

Na modalidade conta garantida, as taxas praticadas pelos bancos estrangeiros no período pré-crise eram 43 p.p. inferiores às dos públicos, e, nos períodos de crise e pós-crise, essa diferença foi reduzida em 30 p.p. e 34 p.p., respectivamente. Em relação aos bancos privados nacionais, as taxas dos estrangeiros eram 7,56 p.p. inferiores no período pré-crise. A diferença aumentou nos períodos de crise e pós-crise em 4,67 p.p. e I2,09 p.p., respectivamente.

Os resultados para as operações de ACC mostram que, em média, as taxas praticadas pelos bancos estrangeiros no período pré-crise são I,52 p.p. inferiores 
às praticadas pelos públicos, e que a diferença é ampliada em I,50 p.p. e I,49 p.p. nos períodos de crise e pós-crise, respectivamente. Na comparação com os bancos privados nacionais, os estrangeiros tinham taxa 2,2 p.p. inferior no período anterior à crise, e essa diferença foi reduzida em I,67 p.p. no período de crise, mas ampliada em 0,5I p.p. no período pós-crise.

A Tabela 9 mostra que os bancos estrangeiros tinham uma taxa de juros média I2,3I p.p. superior à dos públicos no período pré-crise para as operações de crédito pessoal. Essa diferença praticamente dobrou no período de crise e, no período pós-crise, foi aumentada em cerca de 4 p.p. comparada ao período pré-crise. Na comparação com os bancos privados nacionais, os estrangeiros praticavam taxas 8,47 p.p. inferiores no período pré-crise. No período de crise, essa diferença se tornou praticamente nula (com um efeito de 8,78 p.p. da dummy de crise), e, no período pós-crise, os bancos estrangeiros passaram a ter taxas médias 9,22 p.p. maiores que os privados nacionais.

\section{TABELA 9}

DIFERENÇA ENTRE AS TAXAS DE JUROS ANUAIS PRATICADAS PELOS BANCOS DE CONTROLE ESTRANGEIRO E DAS DUAS OUTRAS ESFERAS DE CONTROLE

\begin{tabular}{lcccc}
\hline & \multicolumn{2}{c}{ CRÉDITO PESSOAL } & \multicolumn{2}{c}{ FINANCIAMENTO DE VÉ́CULOS } \\
\cline { 2 - 5 } & ESTR. - PÚBL. & ESTR. - PRIV. & ESTR. - PÚBL. & ESTR. - PRIV. \\
\hline \multirow{2}{*}{ Crise } & $12,38^{* * *}$ & $8,78^{* * *}$ & $2,04^{* *}$ & $-2,32^{* *}$ \\
\cline { 2 - 5 } & $(7,42)$ & $(3,17)$ & $(2,39)$ & $(-2,36)$ \\
\hline Pós-crise & $4,09 * * *$ & $19,19 * * *$ & $2,01 * * *$ & $-1,33^{* *}$ \\
\hline & $(3,44)$ & $(10,07)$ & $(3,09)$ & $(-2,62)$ \\
\hline Constante & $12,31 * * *$ & $-8,47 * * *$ & $-2,1 * * *$ & $-3,15^{* * *}$ \\
\hline R & $(13,07)$ & $(-4,63)$ & $(-3,48)$ & $(-6,80)$ \\
\hline Obs. & 0,364 & 0,488 & 0,100 & 0,105 \\
\hline
\end{tabular}

As colunas “Estr. - Públ." e "Estr. - Priv." referem-se às estimações em que se calculou a variável taxa relativa em relação aos bancos públicos e aos de controle privado nacional, respectivamente. Estatísticas $t$ robustas à heteroscedasticidade estão entre parênteses; * *** e *** indicam significância estatística para os níveis ı०\%, 5\% e 1\%.

Fonte: Elaborada pelos autores com base em dados do Banco Central do Brasil. 
$\mathrm{Na}$ modalidade de financiamento de veículos, os bancos estrangeiros praticavam taxas 2,I p.p. inferiores às dos públicos no período pré-crise, diferença que praticamente se anula nos períodos de crise e pós-crise (efeitos marginais de 2,04 p.p. e 2,oI p.p., respectivamente). Em relação aos bancos privados nacionais, os estrangeiros praticavam taxas 3,I5 p.p. inferiores no período pré-crise, diferença que foi ampliada em 2,32 p.p. no período de crise e I,33 p.p. no período pós-crise (relativamente ao período pré-crise).

De maneira geral, os resultados permitem concluir que os bancos estrangeiros praticam taxas menores que os demais nas três principais modalidades de crédito livre a pessoas jurídicas, em quase todo o período estudado. Já com relação ao crédito à pessoa física, os bancos públicos são aqueles com menores taxas nas operações de crédito pessoal. No financiamento de veículos, as taxas médias de bancos públicos e estrangeiros passaram a ser muito próximas desde setembro de 2008 .

\section{DERIVATIVOS CAMBIAIS}

De acordo com Levine (1996), os bancos estrangeiros podem ter relevância não apenas no mercado de crédito, mas também no oferecimento de serviços especializados e de alta tecnologia agregada. Nesse sentido, é plausível que bancos estrangeiros possuam um pendor natural a oferecer serviços relacionados ao mercado de câmbio (por exemplo, operações no mercado spot, auxílio a captações de empresas brasileiras em moeda estrangeira, oferecimento de produtos para gestão de risco cambial, entre outros).

O mercado de derivativos cambiais é importante e complexo. Há uma miríade de instrumentos disponíveis, incluindo desde aqueles mais simples e padronizados, como os termos de moeda, swaps e contratos futuros, até aqueles mais complexos, como opções flexíveis e contratos feitos sob medida, de acordo com os interesses das contrapartes.

O Gráfico 5 mostra o volume total (em bilhões de USD) de derivativos cambiais, excluindo os contratos a termo de moeda estrangeira ${ }^{\mathrm{I} 2}$, negociados por instituições financeiras no Brasil desde o início de 2006. Nota-se uma retração no volume contratado no último trimestre de 2008 e no trimestre subsequente. Além disso, os volumes contratados não chegam a atingir, no período pós-crise, os níveis dos três primeiros trimestres de 2008 (período pré-crise).

I2 Os contratos a termo foram excluídos desta análise, pois os dados relativos a esses contratos estão disponíveis apenas a partir de março de 2008 . 


\section{GRÁFICO 5}

\section{VOLUME TOTAL NEGOCIADO DE DERIVATIVOS CAMBIAIS $^{\text {I/ }}$ POR ESFERA DE CONTROLE}

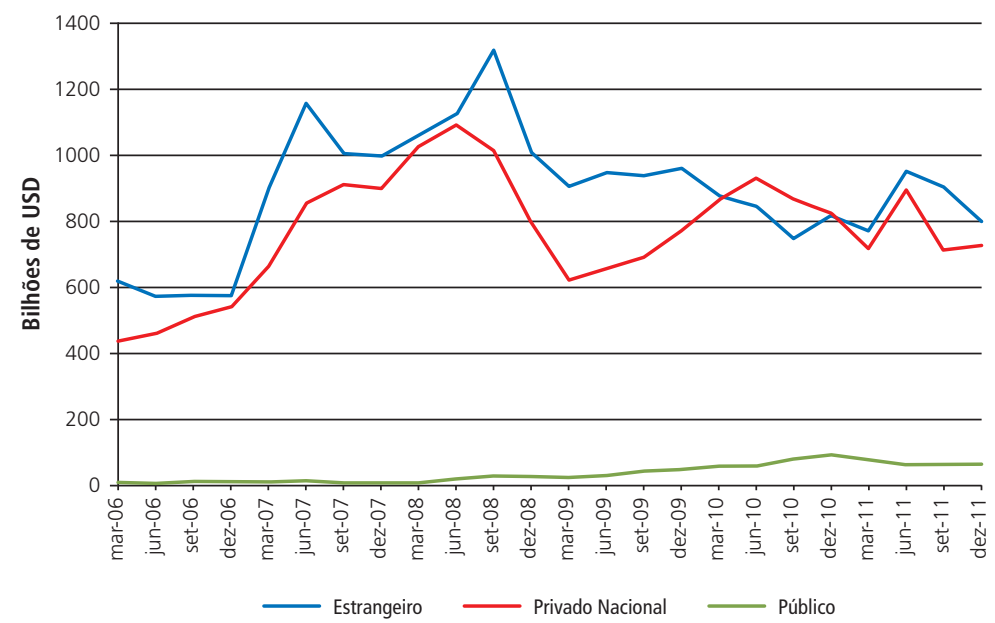

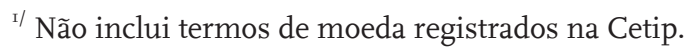

Fonte: Elaborado pelos autores com base em dados da Cetip e BM\&FBovespa.

\section{GRÁFICO 6}

PARTICIPAÇÃO DE MERCADO NO VOLUME TOTAL NEGOCIADO DE DERIVATIVOS CAMBIAIS ${ }^{\text {// }}$ POR ESFERA DE CONTROLE

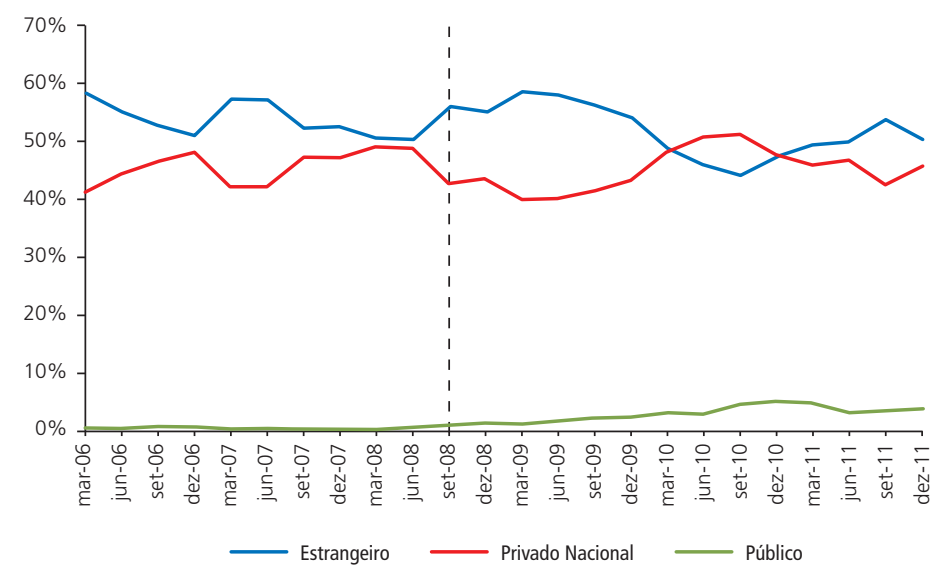

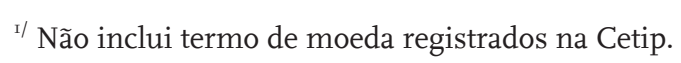

Fonte: Elaborado pelos autores com base em dados da Cetip e BM\&FBovespa. 
O Gráfico 6 apresenta a participação de cada conjunto de bancos no mercado de derivativos cambiais. Observa-se que os bancos de estrangeiros detinham mais de 50\% do mercado no período anterior à crise e mesmo durante o período mais agudo da crise. Durante o ano de 20Io, os estrangeiros reduziram o volume de operações, voltando a ser os maiores desse mercado em 20II. Nota-se que os bancos públicos têm volume negociado pouco relevante se comparados aos demais, embora tenham apresentado crescimento no volume negociado e participação de mercado no período de crise e pós-crise.

O Gráfico 7 mostra volume transacionado nos contratos de swap cambial registrados na Cetip com contrapartes não financeiras. Essa medida é um indicador de como cada conjunto de bancos atende às demandas do setor não financeiro por instrumentos derivativos cambiais. Observa-se que os bancos estrangeiros lideram esse mercado a partir do início de 2009.

\section{GRÁFICO 7}

\section{VOLUME DE SWAPS CAMBIAIS COM CONTRAPARTE NÃO FINANCEIRA}

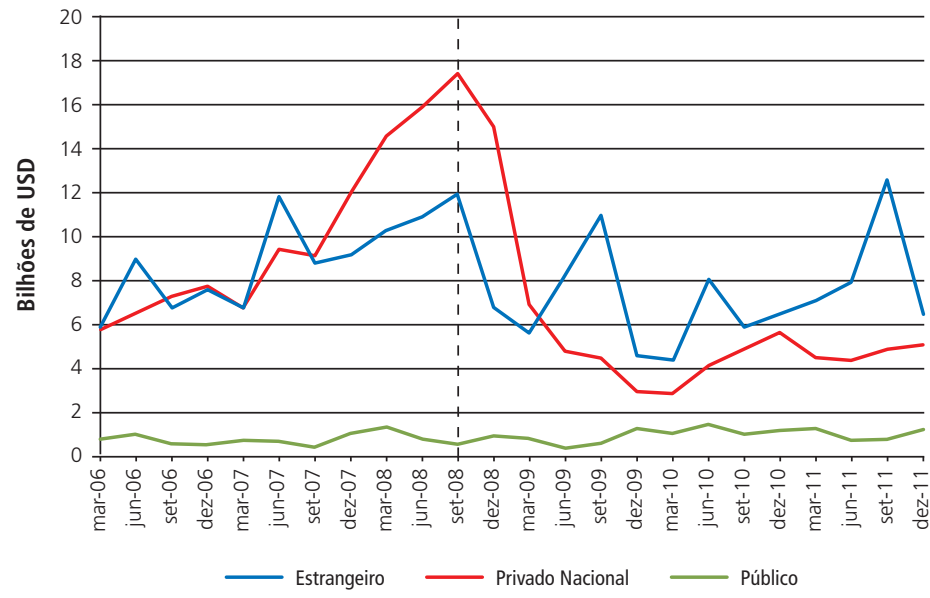

Fonte: Elaborado pelos autores com base em dados da Cetip e BM\&FBovespa.

\subsection{DERIVATIVOS CAMBIAIS E CRISE FINANCEIRA} INTERNACIONAL

A crise financeira de $2008 / 2009$ reverteu abruptamente um processo de valorização do real que se observava desde o início de 2005. Já em setembro de 2008 , tornaram-se públicos casos de empresas não financeiras que sofreram grandes 
perdas devido a exposições a derivativos cambiais. Embora não haja exatidão sobre o tamanho das perdas assumidas pelas companhias brasileiras na ocasião, as estimativas variam entre USD Io bilhões e USD 25 bilhões ("Novos instrumentos para controlar velhas práticas", 2009).

O volume de operações de derivativos cambiais contratadas com o setor não financeiro reduziu-se drasticamente no último trimestre de 2008 e nos períodos subsequentes, em comparação ao período pré-crise. A presente análise não é capaz de atribuir essa redução a um choque de demanda (isto é, empresas não financeiras reduzindo suas operações com derivativos cambiais) ou a um choque de oferta (isto é, os bancos sendo mais seletivos no fornecimento desses contratos). Ainda assim, a análise da participação de mercado dos bancos de cada uma das esferas de controle pode trazer informações importantes sobre a atuação de cada um deles.

A Equação (3) é estimada para cada conjunto, considerando o volume total de swaps, além das operações com contrapartes não financeiras e investidores institucionais. Os resultados das estimações são mostrados na Tabela ıo.

\section{TABELA IO}

SWAPS COM REGISTRO NA CETIP - PARTICIPAÇÃO DE MERCADO ALTERAÇÕES NA CRISE E NO PERÍODO PÓS-CRISE

\begin{tabular}{lcccccccc}
\hline & \multicolumn{2}{c}{ TODAS AS CONTRAPARTES } & \multicolumn{3}{c}{ NÃO FINANCEIRAS } & \multicolumn{2}{c}{ INV. INSTITUCIONAIS } \\
\hline & $(1)$ & $(2)$ & $(3)$ & $(4)$ & $(5)$ & $(6)$ & $(7)$ & $(8)$ \\
\hline & ESTRANG. & PÚBLICOS & $\begin{array}{c}\text { PRIVADOS } \\
\text { NACIONAIS }\end{array}$ & ESTRANG. & PÚBLICOS & $\begin{array}{c}\text { PRIVADOS } \\
\text { NACIONAIS }\end{array}$ & ESTRANG. & $\begin{array}{c}\text { PRIVADOS } \\
\text { NACIONAIS }\end{array}$ \\
\hline \multirow{2}{*}{ Crise } & $0,106 * *$ & $-0,004$ & $-0,103 * *$ & $-0,006$ & $-0,001$ & 0,007 & $0,201 * * *$ & $-0,201 * * *$ \\
\cline { 2 - 9 } & $(2,338)$ & $(-0,683)$ & $(-2,369)$ & $(-0,134)$ & $(-0,128)$ & $(0,164)$ & $(3,675)$ & $(-3,674)$ \\
\hline Pos-crise & $0,176 * * *$ & $0,027 * * *$ & $-0,202 * * *$ & $0,111 * * *$ & $0,045 * * *$ & $-0,156 * * *$ & $0,153 * * *$ & $-0,153 * * *$ \\
\cline { 2 - 9 } & $(8,982)$ & $(4,706)$ & $(-11,066)$ & $(4,531)$ & $(4,747)$ & $(-7,012)$ & $(3,525)$ & $(-3,525)$ \\
\hline Constante & $0,513 * * *$ & $0,027 * * *$ & $0,460 * * *$ & $0,454 * * *$ & $0,041 * * *$ & $0,504 * * *$ & $0,727 * * *$ & $0,273 * * *$ \\
\cline { 2 - 9 } & $(40,306)$ & $(10,731)$ & $(37,128)$ & $(35,286)$ & $(9,825)$ & $(37,580)$ & $(17,628)$ & $(6,635)$ \\
\hline Observ. & 72 & 72 & 72 & 72 & 72 & 72 & 72 & 72 \\
\hline R & 0,475 & 0,304 & 0,573 & 0,239 & 0,295 & 0,419 & 0,204 & 0,204 \\
\hline
\end{tabular}

Estatísticas $t$ robustas à heteroscedasticidade estão entre parênteses; * ** e *** indicam significância estatística para os níveis ı०\%, 5\% e I\%.

Fonte: Elaborada pelos autores com base em dados da Cetip. 
As três primeiras colunas da Tabela io mostram que, no período anterior à crise, do total de swaps cambiais negociados, os bancos estrangeiros respondiam, em média, por 51,3\% do mercado, em termos do volume negociado, ante $46,0 \%$ dos privados nacionais e apenas 2,7\% dos públicos. Durante o período de crise, enquanto a participação de bancos públicos não se altera, bancos estrangeiros elevam sua participação de mercado em Io,6 p.p. em detrimento dos bancos privados nacionais. Após a crise, a participação de mercado dos bancos estrangeiros atinge $68,9 \%$, em média, enquanto o market share dos bancos privados nacionais se reduz a $25,8 \%$. Por sua vez, os bancos públicos praticamente dobram sua participação de mercado no período pós-crise com 5,4\% do volume de swaps negociados na Cetip.

Quando as operações com contrapartes não financeiras (colunas 4 a 6) são analisadas, observa-se que, no período pré-crise, os bancos estrangeiros respondiam por $45,4 \%$ do mercado, ante $50,4 \%$ dos privados nacionais e $4,1 \%$ dos públicos. Durante a crise, não se vê alteração significativa na estrutura do mercado, porém, no período pós-crise, os estrangeiros aumentaram sua participação em cerca de II,I p.p. relativamente ao período pré-crise. Os bancos públicos também aumentaram sua participação no período pós-crise em 4,5 p.p., mais do que dobrando sua participação de mercado.

Com relação aos swaps contratados com investidores institucionais (colunas 7 e 8), os bancos estrangeiros possuíam, antes da crise, participação de mercado média mensal de $72,7 \%$. Relativamente ao período anterior à crise, essa participação aumentou em 20,I p.p. durante a crise e I5,3 p.p. no período pós-crise. Os resultados para os bancos públicos não foram reportados, pois sua participação nesse mercado é inferior a o,I\%.

\section{CONCENTRAÇÃO DOS MERCADOS DE CRÉDITOS LIVRES E DERIVATIVOS CAMBIAIS}

Esta seção analisa a estrutura dos mercados de crédito e derivativos cambiais utilizando como métrica o Índice de Herfindahl-Hirschman (HHI). Essa medida é utilizada na literatura de economia bancária para medir concentração de mercado e consiste no somatório do quadrado das participações de mercado de cada participante na indústria ${ }^{\mathrm{I}}$. O Gráfico 8 mostra a evolução do HHI para os mercados de crédito livre e derivativos cambiais.

I3 Para a revisão da literatura empírica sobre concentração de mercado, ver Degryse e Ongena (2008). 
Os dados mostram que o mercado de crédito é mais concentrado que o de derivativos cambiais, independentemente do período analisado. Os índices de concentração sugerem que os grandes bancos têm maior participação no mercado de crédito, enquanto a atuação dos bancos com maior foco em atividades de tesouraria torna o mercado de derivativos menos concentrado. Vale ressaltar a ocorrência de duas fusões importantes no último trimestre de 2008: a primeira entre bancos privados nacionais (Itaú e Unibanco) e a segunda entre bancos estrangeiros (ABN Amro e Santander), que ajudam a explicar a elevação abrupta no final de 2008 . A crise financeira teve maior impacto na concentração do mercado de crédito, pois, no período pós-crise, o mercado de derivativos retorna a níveis de concentração muito próximos do período pré-crise.

\section{GRÁFICO 8}

EVOLUÇÃO DA CONCENTRAÇÃO DOS MERCADOS DE CRÉDITO LIVRE E DERIVATIVOS CAMBIAIS

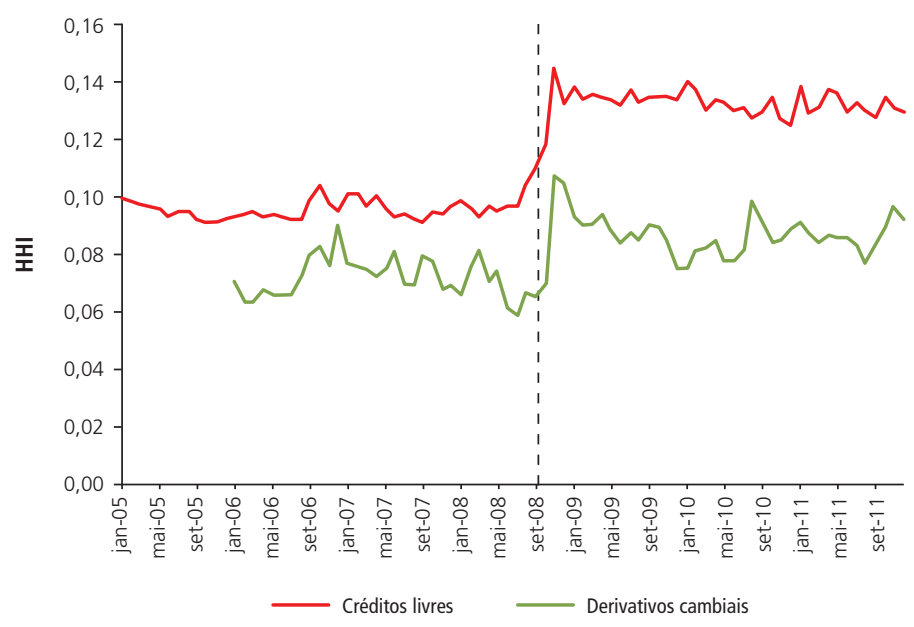

Fonte: Elaborado pelos autores com base em dados do Banco Central do Brasil, da Cetip e BM\&FBovespa.

Embora idealmente proposto para avaliar cada mercado de uma maneira geral, utilizamos também o HHI como medida de concentração de cada conjunto de bancos (medida de concentração intragrupo). A Tabela II mostra os valores médios de HHI para os mercados de crédito livre e de derivativos cambiais para os três períodos considerados: antes, durante e após a crise financeira. 
TABELA II

CONCENTRAÇÃO DE MERCADO POR

CONJUNTO DE BANCOS - HHI

\begin{tabular}{lcccccc}
\hline & \multicolumn{1}{c}{ BANCOS ESTRANGEIROS } & \multicolumn{2}{c}{$\begin{array}{c}\text { BANCOS PRIVADOS } \\
\text { NACIONAIS }\end{array}$} & \multicolumn{2}{c}{ BANCOS PÚBLICOS } \\
\cline { 2 - 7 } & $\begin{array}{l}\text { CRÉDITO } \\
\text { LIVRE }\end{array}$ & $\begin{array}{c}\text { DERIVATIVOS } \\
\text { CAMBIAIS }\end{array}$ & $\begin{array}{c}\text { CRÉDITO } \\
\text { LIVRE }\end{array}$ & $\begin{array}{c}\text { DERIVATIVOS } \\
\text { CAMBIAIS }\end{array}$ & $\begin{array}{c}\text { CRÉDITO } \\
\text { LIVRE }\end{array}$ & $\begin{array}{c}\text { DERIVATIVOS } \\
\text { CAMBIAIS }\end{array}$ \\
\hline Antes da crise & 0,20 & 0,09 & 0,23 & 0,22 & 0,47 & 0,90 \\
\hline Crise & 0,32 & 0,12 & 0,34 & 0,29 & 0,46 & 0,62 \\
\hline Pós-crise & 0,35 & 0,14 & 0,32 & 0,23 & 0,48 & 0,62 \\
\hline
\end{tabular}

Os índices reportados consistem no valor médio dos HHI mensais para os períodos considerados. Para o mercado de crédito, os dados iniciam em janeiro de 2005 e, para o de derivativos, em janeiro de 2006.

Fonte: Elaborada pelos autores com base em dados do Banco Central do Brasil, da Cetip e BM\&FBovespa.

No conjunto de bancos estrangeiros, o mercado de crédito é bem mais concentrado que o de derivativos. No conjunto de bancos privados nacionais, o mercado de derivativos é menos concentrado que o de crédito, porém as diferenças são menores do que no de estrangeiros. Os índices de concentração do conjunto de bancos públicos destoam dos demais, por causa do pequeno número de instituições e da diferença de tamanho entre os dois principais bancos públicos federais (Banco do Brasil e Caixa Econômica Federal) e os demais bancos públicos.

A Tabela II mostra que o conjunto de bancos estrangeiros é menos concentrado na negociação de derivativos em relação aos demais conjuntos. Isso permite concluir que a maior pulverização do mercado de derivativos cambiais em relação ao mercado de crédito deve-se à participação relevante de bancos estrangeiros de menor porte.

\section{CONSIDERAÇÕES FINAIS}

Neste estudo, investigou-se a atuação dos bancos de controle estrangeiro que atuam no Brasil, com foco em dois tipos de serviços financeiros: a concessão de crédito e a oferta de instrumentos financeiros derivativos cambiais. Verificaram-se, ainda, os impactos da crise financeira internacional de 2008/2009 
sobre o comportamento desses bancos. Embora nossos testes não permitam concluir relações de causa e efeito entre variáveis, os resultados sugerem fortemente a transmissão temporária do choque de liquidez ocorrido em países desenvolvidos após a falência do banco Lehman Brothers.

Os bancos de controle estrangeiro têm papel relevante no mercado de créditos livres referenciais para taxa de juros, respondendo por pouco mais de um quarto das concessões, à frente dos bancos públicos. A crise financeira afetou negativamente os bancos de controle estrangeiro, de forma mais intensa e por um maior período de tempo do que os bancos privados nacionais. Entretanto, a partir do terceiro trimestre de 2010 até o final de 20II, a taxa de crescimento das concessões dos estrangeiros foi superior às dos bancos de controle nacional.

Entre as mais importantes modalidades de créditos livres, as taxas de juros cobradas pelos bancos estrangeiros para pessoas jurídicas são, em média, inferiores às taxas cobradas pelos bancos privados nacionais e públicos, o que pode sugerir que esses bancos se relacionam com clientes com menor risco de crédito. No período da crise, os estrangeiros ampliaram essa diferença perante os bancos privados nacionais na modalidade conta garantida. Já no crédito à pessoa física, os bancos estrangeiros e os públicos se alternam ao longo do tempo no oferecimento da menor taxa média na modalidade de empréstimo para aquisição de veículos. Em relação ao crédito pessoal, até a crise, os bancos estrangeiros cobravam taxas superiores às dos bancos públicos, mas inferiores às dos bancos privados nacionais. A partir da crise, os estrangeiros passaram a cobrar taxas de juros superiores aos bancos privados nacionais nessa modalidade.

No que se refere ao mercado de derivativos cambiais, os bancos estrangeiros, inclusive os de menor porte, têm papel importante no fornecimento desses instrumentos para o setor não financeiro. Adicionalmente, os resultados mostram que esse mercado é menos concentrado que o mercado de crédito.

Embora, durante a crise, não se observe alteração significativa na participação de mercado dos três grupos de bancos nos swaps com contraparte não financeira, os bancos estrangeiros aumentam seu market share nesse mercado no período pós-crise.

De modo geral, pode-se notar que os bancos de controle estrangeiro têm um importante papel no sistema bancário brasileiro. Apesar de a crise ter afetado negativamente a participação desses bancos nos volumes de créditos concedidos, não houve redução na participação no mercado de derivativos cambiais. Finalmente, como o período amostral não incluiu períodos de crise de origem doméstica, não foi possível verificar se os bancos estrangeiros conseguem cumprir a importante missão de atenuar o impacto pró-cíclico de uma crise doméstica nesse cenário. 


\section{THE ROLE OF FOREIGN BANKS IN BRAZIL: CREDIT AND DERIVATIVES MARKETS FROM 2005 TO 20 II}

\section{ABSTRACT}

This study relates to the debate concerning the consequences of the presence of foreign banks in emerging countries. Specifically, this study investigates the role of the group of foreign banks in Brazil between 2005 and 20II, focusing on their activity on foreign exchange derivatives and credit markets. Additionally, it examines the impacts of the international financial crisis of 2008/2009 on bank behavior. The motivation behind this analysis lies on the role of credit and financial risk management on economic development. Foreign banks may impact the rate of growth of the domestic economy by improving credit access to firms. Foreign banks may also have a positive effect in emerging markets by offering foreign exchange derivatives to companies and investors, which are important tools among the set of risk management technologies. In Brazil, foreign banks account for almost a quarter of the supply of non-directed credit during the sample period. Although this analysis does not pertain to causal inference, it indicates that the financial crisis negatively affected the supply of loans by foreign banks, even more intensively and longer than domestic private banks. This observation suggests that the liquidity shock that occurred in developed markets was transmitted to the Brazilian economy. Nevertheless, in the post-crisis period, namely from the third quarter 20I0 until the end of 20II, the growth rate of foreign banks' lending was larger than those of other banks. In the currency derivatives market, foreign banks, including the smaller ones, play an important role in providing such instruments, especially for the non-financial sector. The results show that, during the crisis and especially in the post-crisis period, domestic private banks reduced their share in such markets. Moreover, we show that this market is less concentrated than the credit market, which is evidence for the importance of the existence of smaller financial institutions.

\section{KEYWORDS}

Foreign banks. Credit. Currency derivatives. Crisis transmission. Brazilian economy. 


\section{ACTUACIÓN DE LOS BANCOS EXTRANJEROS EN BRASIL: MERCADOS DE CRÉDITO Y DERIVATIVOS DE 2005 A $201 I$}

\section{RESUMEN}

Este estudio se incluye en el debate con relación a las consecuencias de la presencia de bancos extranjeros en países en desarrollo. Específicamente, se investiga la actuación del conjunto de bancos de control extranjero en Brasil del 2005 a 20II, con foco en su participación en los mercados de crédito y de derivativos cambiales. Se verificaron también los impactos de la crisis financiera internacional de 2008/2009 sobre el comportamiento de esos bancos. La motivación para este análisis se encuentra en los papeles de crédito y en la gestión de riesgos financieros que se desempeñan en el desarrollo económico. El crédito es un canal fundamental de actuación por el cual los bancos extranjeros pueden afectar el crecimiento de la economía doméstica. Los derivativos cambiales hacen parte del importante conjunto de tecnologías para la gestión de riesgo de las empresas y de los inversores que son más comúnmente ofrecidos por los bancos extranjeros y ayudan a explicar los efectos benéficos de la presencia de estos bancos en economías emergentes. En el periodo de muestra, los bancos extranjeros responden por poco más de un cuarto de las concesiones de crédito libre. Aunque las pruebas realizadas no permiten concluir relaciones de causa y efecto entre las variables, se observa que la crisis financiera afectó negativamente a los bancos extranjeros, en forma más intensa y larga que a los bancos privados nacionales. Esta observación puede ser indicativa de una transmisión del choque de liquidez ocurrido en los mercados desarrollados para la economía brasileña. Entre tanto, en el periodo pos crisis, a partir del tercer trimestre de 2010 hasta fines de $201 \mathrm{II}$, la tasa de crecimiento de las concesiones de los extranjeros fue superior a las de los nacionales. En el mercado de derivativos cambiales, los bancos extranjeros, inclusive los de menor porte, tienen un papel importante en la provisión de estos instrumentos, especialmente para el sector no-financiero. Los resultados muestran que, durante la crisis, y, especialmente, en el periodo pos-crisis, los bancos privados nacionales disminuyeron su actuación en estos mercados. Adicionalmente, se muestra que ese mercado es menos concentrado que el mercado de crédito, lo que evidencia la importancia de la existencia de instituciones financieras de menor porte.

\section{palabras clave}

Bancos extranjeros. Crédito. Derivativos cambiales. Transmisión de crisis. Economía brasileña. 


\section{REFERÊNCIAS}

Ait-Sahalia, Y., Andritzky, J., Jobst, A., Nowak, S., \& Tamirisa, N. (20I2). Market response to policy initiatives during the global financial crisis. Journal of International Economics, 87(I), I62-I77.

Allen, F., Hryckiewicz, A., Kowalewski, O., \& Tumer-Alkan, G. (20I2, January) Transmission of bank liquidity shocks in loan and deposit markets: the role of interbank borrowing and market monitoring [Working Paper $\mathrm{N}^{\circ}$ IO-28]. Wharton Financial Institutions Center. Retrieved December 4, 2013, from http://ssrn.com/abstract=I707591.

Annibal, C., Lundberg, E., \& Koyama, S. M. (2009). Crise de 2008 e as mudanças no mercado de crédito. Relatório de Economia Bancária e Crédito, Banco Central do Brasil. Recuperado em 4 dezembro, 2013, de http://www.bcb.gov.br/pec/depep/spread/REBC2009.pdf.

Banco Central do Brasil. (20I0, setembro). Relatório de estabilidade financeira. Recuperado em 4 dezembro, 20I3, de http://www.bcb.gov.br/htms/estabilidade/2010_09/refinp.pdf.

Banco Central do Brasil. (20II, setembro). Relatório de estabilidade financeira. Recuperado em 4 dezembro, 20I3, de http://www.bcb.gov.br/htms/estabilidade/20II_09/refP.pdf.

Beck, T., \& Martinez Peria, M. S. (2007). Foreign bank acquisitions and outreach: evidence from Mexico [Working Paper, $\mathrm{N}^{\circ}$ 4467]. World Bank Policy Research. Retrieved December 4, 2013, from http://www.imf.org/external/np/seminars/eng/2008/strureform/pdf/bkacq.pdf.

Bevilaqua, A. S., \& Loyo, E. (I998). Openness and efficiency in Brazilian banking (Texto para discussão, $\mathrm{N}^{\circ}$ 390). Rio de Janeiro: Departamento de Economia da PUC-Rio. Recuperado em 4 dezembro, 20I3, de http://www.econ.puc-rio.br/pdf/td390.pdf.

Brunnermeier, M. K. (2009). Deciphering the liquidity and credit crunch 2007-2008. Journal of Economic Perspectives, 23(I), 77-IOO.

Cetorelli, N., \& Goldberg, L. S. (20II). Global banks and international shock transmission: evidence from the crisis. International Monetary Fund Economic Review, 59(I), 4I-76.

Cetorelli, N., \& Goldberg, L. S. (20I2). Banking globalization and monetary transmission. Journal of Finance, 67(5), I8II-I843.

Chava, S., \& Purnanandam, A. (20II). The effect of banking crisis on bank-dependent borrowers. Journal of Financial Economics, 99(I), II6-I35.

Claessens, S., Demirgüç-Kunt, A., \& Huizinga, H. (200I). How does foreign entry affect the domestic banking market? Journal of Banking and Finance, 25(5), 89I-9II.

Claessens, S., \& Van Horen, N. (20I2). Foreign banks: trends, impact and financial stability [Working Paper $\mathrm{N}^{\circ}$ I2/IO]. International Monetary Fund.

Clarke, G., Cull, R., Martinez Peria, M. S., \& Sanchez, S. (2003). Foreign bank entry: experience, implications for developing countries, and agenda for further research. World Bank Research Observer, $18(\mathrm{I})$, 25-40.

Coutinho, E. S., \& Amaral, H. F. (2010, janeiro/junho). Abertura ao capital estrangeiro e desempenho no setor bancário brasileiro no período 2001/2005. Revista de Administração de Empresas - eletrônica, 9(I).

Crystal, J. S., Dages, B. G., \& Goldberg, L. S. (200I). Does foreign ownership contribute to sounder banks in emerging markets? The Latin American experience. In R. E. Litan, P. R. Masson $\&$ M. Pomerleano. Open doors: foreign participation in financial systems in developing countries (pp. 2I7-266). Washington, DC: Brookings Press. 
Cull, R., \& Martinez Peria, M. S. (2010). Foreign bank participation in developing countries: what do we know about the drivers and consequences of this phenomenon? [Working Paper $\mathrm{N}^{\circ} 5398$ ]. The World Bank. Retrieved December 4, 20I3, from http://www.wds.worldbank.org/external/ default/WDSContentServer/WDSP/IB/20I0/08/09/000I58349_20100809094056/Rendered/ PDF/WPS5398.pdf.

Dawid, P. E., \& Takeda, T. (20II). Recolhimentos compulsórios e o crédito bancário brasileiro (Trabalhos para discussão, $\mathrm{N}^{\circ}$ 250). Banco Central do Brasil. Recuperado em 4 dezembro, 20I3, de http:// www.bcb.gov.br/pec/wps/port/td250.pdf.

Degryse, H., \& Ongena, S. (2008). Competition and regulation in the banking sector: a review of the empirical evidence on the sources of bank rents. In A. V. Thakor \& A. W. A. Boot (Eds.). Handbook of financial intermediation and banking. Amsterdam: Elsevier.

De Haas, R., \& Van Lelyveld, I. (20IO). Internal capital markets and lending by multinational bank subsidiaries. Journal of Financial Intermediation, 19(I), I-25.

De Haas, R., \& Van Lelyveld, I. (20II). Multinational banks and the global financial crisis: weathering the perfect storm? [Working Paper $\mathrm{N}^{\circ}$ I35]. European Bank for Reconstruction and Development. Retrieved December 4, 20I3, from http://www.ebrd.com/downloads/research/economics/workingpapers/wpor35.pdf.

Detragiache, E., Tressel, T., \& Gupta, P. (2008, October) Foreign banks in poor countries: theory and evidence. The Journal of Finance, 59(5), 2123-2160.

Fachada, P. (2008). Foreign bank's entry and departure: the recent Brazilian expericence (1996-2006) (Trabalhos para discussão, $\mathrm{N}^{\circ} \mathrm{I} 64$ ). Banco Central do Brasil. Recuperado em 4 dezembro, 20I3, de http://www.bcb.gov.br/pec/wps/ingl/wpsi64.pdf.

Gatev, E., \& Strahan, P. E. (2006). Banks' advantage in hedging liquidity risk: theory and evidence from the commercial paper market. The Journal of Finance, 61(2), 867-892.

Goldberg, L. S. (2009). Understanding banking sector globalization. International Monetary Fund Staff Papers, 56(I), I7I-I97.

Guimarães, P. (2002). How does foreign entry affect the domestic banking market? The Brazilian case. Latin American Business Review, 3(4), I2I-I4O.

Kashyap, A. K., Rajan, R. G., \& Stein, J. C. (2002). Banks as liquidity providers: an explanation for the co-existence of lending and deposit-taking. The Journal of Finance, 57(I), 33-74.

Levine, R. (1996). Foreign banks, financial development, and economic growth. In C. E. Barfield (Ed.). International financial markets: harmonization versus competition. Washington: The AEI Press. Martinez Peria, M. S., \& Mody, A. (2004). How foreign participation and market concentration impact bank spreads: evidence from Latin America. Journal of Money, Credit and Banking, 36(I), 5II-537.

Martinez Peria, M. S., Powell, A., \& Vladkova Hollar, I. (2002). Banking on foreigners: the behavior of international bank lending to Latin America, I985-2000 [Working Paper $\mathrm{N}^{\circ} 2893$ ]. World Bank, Washington, DC. Retrieved December 4, 2013, from http://papers.ssrn.com/sol3/ papers.cfm?abstract_id $=636256$.

Mishkin, F. S. (2006). The next great globalization: how disadvantaged nations can harness their financial systems to get rich. New Jersey: Princeton University Press.

Montoro, C., \& Rojas-Suarez, L. (20I2). Credit at times of stress: Latin American lessons from the global financial crisis [Working Paper $\mathrm{N}^{\circ} 370$ ]. Retrieved December 4, 2013, from http://www.bis. org/publ/work370.pdf. 
Novos instrumentos para controlar velhas práticas. (2009, novembro I9). Valor Econômico, p. A-I6. Popov, A., \& Udell, G. F. (2010). Cross-border banking and the international transmission of financial distress during the crisis of 2007-2008 [Working Paper $\mathrm{N}^{\circ}$ I203]. European Central Bank. Retrieved December 4, 20I3, from http://www.ecb.europa.eu/pub/pdf/scpwps/ecbwpi203.pdf.

Rodrik, D., \& Subramanian, A. (2009). Why did financial globalization disappoint? International Monetary Fund Staff Papers, 56 (I), II2-138.

Schnabl, P. (20I2). The international transmission of bank liquidity shocks: evidence from an emerging market. The Journal of Finance, 68(3), 897-932.

Stiglitz, J. (2005). Finance for development. In M. D. Ayogu, \& D. Ross. Development dilemmas: the methods and political ethics of growth policy. London: Routledge.

Teles, A. S. (20II). Banking internationalization in Latin America: the Brazilian case, 1997- 2007 a panel analysis. Dissertação de mestrado, Universidade Técnica de Lisboa, Portugal. Recuperado em 4 dezembro, 2013, de https://www.repository.utl.pt/bitstream/ı0400.5/3427/I/Tese_-_Andrea_ Teles.pdf. 